\title{
Well-Being during a Time of Change: Timor-Leste on the Path to Independence
}

\author{
Kaspar Richter \\ World Bank, 1818 H Street NW, Washington, DC 20433, USA ${ }^{1,2}$
}

\begin{abstract}
Countries undergoing fundamental economic and political transformations might experience differential adjustments in material well-being and empowerment. This paper evaluates self-rated welfare and power changes in Timor-Leste, covering the period from prior to the 1999 referendum on independence from Indonesia to the eve of independence in end 2001. Drawing on the first nationally representative household survey and village census, it demonstrates how subjective, objective and recall information can be combined to provide a rich profile of trends in well-being from the pre- to post-conflict stage. The analysis shows that changes in self-rated welfare and power broadly corresponded to changes recorded by objective indicators. While economic well-being improved little, empowerment increased dramatically. The changes were not uniform across the population but some groups benefited more than others. The evidence for Timor-Leste is consistent with these hypotheses: economic resources increase welfare, and more than power; social resources increase power, and more than welfare; welfare winners have low initial economic resources; power winners have high social resources; and economic shocks reduce welfare and power, but welfare more than power.
\end{abstract}

Key words: Subjective welfare, Power, Timor-Leste

1 Email:krichter@worldbank.org. I would like to thank Benu Bidani, Martin Cumpa, Berk Ozler and participants at the 2004 Minnesota Development Economics conference for valuable discussions and comments.

2 JEL classification numbers: I30, O10

Preprint submitted to Elsevier Preprint December 2004 


\section{Introduction}

Individual welfare is a multidimensional concept. Economists tend to favour measures of well-being that are closely oriented on economic theory, such as consumption or income. Yet, going beyond these standard measures is useful for various reasons. Following Sen (1999), increasing economic resources is essential as a means to enhancing individual welfare, but it is just an instrument and not the desired outcome. The overarching objective is the expansion of real freedoms, or capabilities, enjoyed by the members of the society.

Even a wider array of objective measures is unlikely to capture the notion of well-being adequately. Interpersonal comparisons of welfare cannot be made by looking solely at the "revealed" preferences of people as evident from their demand behaviour (Pollack and Wales (1979) and Browning (1992)). This has severe consequences. As is well know from Arrow's Impossibility Theorem (Arrow (1950)), a social welfare function cannot be constructed in the absence of interpersonal comparisons of individual welfare.

In addition, participatory poverty assessments around the world have shown that a good life or well-being has both material and psychological dimensions. It includes aspects of "empowerment", or the effective inclusion of people in making decisions on economic, social, cultural and political issues. ${ }^{3}$ Lack of voice, discrimination, social barriers, mistreatment by public officials, alienation from service providers, and language barriers all affect the ability of individuals to achieve their potential and create a sense of powerlessness. While economic well-being and empowerment are related, they represent separate and imperfectly correlated concepts.

A separate consideration of economic well-being and power is especially important when nations embrace systemic institutional reforms. The fall of the Berlin Wall in 1989 gave rise to political and economic liberalization in Eastern Europe, the Former Soviet Union, and in most countries of Africa and many nations in East Asia. Such reforms are likely to have different impacts on economic and power status. Not everybody benefits in the same way, and some even lose out, as traditional values or authority structures are challenged, and the stakes of economic competition are raised. In particular, while the move toward greater political participation may result in higher trust and representation of large parts of the population, disruptions to the inherited economic structure and a slow emergence of new economic opportunities can worsen

$\overline{3}$ For example, World Bank (2001) characterizes poverty along four dimensions, including opportunity, human development, vulnerability, and empowerment. Empowerment is defined as "...the expansion of assets and capabilities of poor people to participate in, negotiate with, influence, control, and hold accountable institutions that affect their lives" (World Bank (2002b)). 
material welfare at least in the short term, especially for groups with large stakes in the old economic system. Standard economic and social statistics are unlikely to do justice to the significance of this adjustment and to capture adequately the empowerment dimension.

In view of these shortfalls of objective welfare measures, a substantive volume of research has emerged over the last decades that uses people's own assessments to get at notions of individual well-being. The underlying idea is to rely on individuals and households themselves to define the level of well-being. Even though precise definitions of these concepts still remain elusive, psychologists and economists have used self-assessments as proxy measures of welfare and well-being. The approach has become so successful that subjective questions are now routinely included in household surveys, along with objective measures.

The distinguishing feature of subjective measures is that they are based on a person's self-assessment. This raises the question whether they are consistent and change systematically with objective measures. For example, a person's self-assessed economic situation may stay unchanged even though her consumption increases, either because her expectations have increased or because her position relative to her reference group has remained the same. To avoid such pitfalls in the assessment of well-being across a group of individuals on the basis of subjective indicators, one needs to assume that individuals:

- are able to understand and answer consistently questions about own situation, and

- provide responses that are comparable.

While some evidence suggests that these conditions typically hold within a common cultural context, it is generally difficult to verify these assumptions. Furthermore, the reliability of any given welfare indicator can be severely undermined by measurement problems (Deaton (1997)). Therefore, it is important to validate whether observed changes are real or reflect data problems (Baulch and Hoddinott (2000)). One possibility is to investigate whether covariates display a similar pattern. Therefore, an analysis of subjective measures is best conducted jointly with an investigation of objective indicators, drawing on a wide range of welfare measures.

Timor-Leste became the first new state of the third millennium on May 20, 2002 , following a quarter century of occupation. The population endorsed the birth of this nation on August 30, 1999 when, with a turnout of 98 percent, 78.5 percent of the registered electorate voted for independence from Indonesia. The announcement of the ballot results was followed by violence that wreaked physical destruction and human terror throughout the territory. Up to threequarters of the population was displaced in the weeks following the ballot 
results, large parts of physical infrastructure were destroyed or rendered inoperable, and GDP in 1999 declined by about 40 percent (World Bank (2002a)). Soon after the violence ceased, Timor-Leste began rebuilding itself with the establishment of a United Nations transitional administration and support from the international donor community and NGOs. During 2000 and 2001, Timor-Leste made enormous progress in rehabilitating its economy, with GDP growing at an annual rate of 15 to 20 percent, reconstructing infrastructure, reintegrating refugees and building the key elements of a sustainable political process in an environment of internal peace. This transition has transformed people's lives fundamentally and in ways that go far beyond purely material endowments. Although the fundamental achievement of gaining independence is overwhelmingly positive, the vast structural changes were accompanied by conflict, destruction, and displacement.

This paper is an empirical study of changes in economic well-being ('welfare') and empowerment ('power') in Timor-Leste from the pre- to post-conflict period. ${ }^{4}$ It draws on the only nationally representative household survey and community census of Timor-Leste to investigate the impact of the systemic changes between the violence of 1999 to end-2001, six months before independence. It demonstrates how subjective and objective measures, based on current and recall information, can be used to develop a differentiated profile of changes in well-being from the pre- to post-conflict period. ${ }^{5}$

However, in interpreting the findings, it is important to bear in mind one qualification. Recall data are not representative of the historic population in case of large population changes. This is likely to be the case in Timor-Leste, where parts of the population left the country for good - in particular Indonesians and supporters of the old regime. The results in this paper therefore reflect changes in well-being as perceived by the 2001 population rather than the 1999 population.

The rest of the paper is organized as follows. The next section describes the data. Section 3 takes a first look at the pattern of changes in self-rated welfare and power between 1999 and 2001. Section 4 investigates the determinants of welfare and power in 2001, and Section 5 analyzes the changes in welfare and power. The final section concludes.

$\overline{4}$ The terminology is adopted from Lokshin and Ravallion (2002) who analyze subjective welfare and power in Russia, focusing on the differential impacts of individual income, household income and income inequality. Frey and Stutzer (2000) argue that direct democracy and federal structure raise self-reported well-being in Switzerland and ? finds that the quality of goverment matter for happiness. These two papers do not separate between welfare and power.

5 In the following, I will use ' 1999 ' to refer to the date before the violence of September 1999, and '2001' to end 2001, the time of the fielding of the TLSS. 


\section{Data}

To assess the profound changes in the lives of people and prepare the national plan for post-independence, the transitional government, supported by the donor community, initiated new surveys. ${ }^{6}$ The analysis of this paper draws on the two new principal data sources. The Timor-Leste Living Standard Measurement Survey (TLSS) is a national representative sample of 1,800 households from 100 communities ("Suco") and 300 villages ("Aldeia") covering over one percent of the population. ${ }^{7}$ The survey was designed to diagnose the extent, nature and causes of poverty, and to analyse policy options facing the country. It assembles comprehensive information on household demographics, housing and assets, household expenditures and income, agriculture, employment, health and education, and subjective perceptions of poverty, well-being and social capital. Data collection was undertaken between end August and early December 2001.

The TLSS was complemented by a census of all Sucos in the country, conducted during February to April 2001. It provides an inventory of social and physical infrastructure and of the economic characteristics of Suco and Aldeias, in addition to population estimates.

Both surveys relied extensively on recall questions to establish a baseline for well-being prior to the referendum in 1999 for three reasons. First, there were concerns regarding the reliability of existing Indonesian data for Timor Leste. Second, little historic information was available on subjective measures of well-being. Third, due to large population displacement and migration, the population as of end 2001 was unlikely to be directly comparable to the population prior to the referendum in 1999.

\footnotetext{
6 The data was collected by the Poverty Assessment Project, which was a partnership between the Planning Commission of the Timor Leste Transitional Authority with the World Bank, the Asian Development Bank, the United Nations Development Programme, and the Japanese International Cooperation Agency. Benu Bidani managed the fielding and analysis of the TLSS (World Bank (2003)).

7 Timor-Leste is divided into 13 major units called Distritos (districts). These are further subdivided into 67 Postos (sub-districts), 498 Sucos (villages) and 2,336 Aldeias (hamlets) (Munoz (2001)).
} 


\section{Mobility}

\subsection{Methodology}

This paper analyzes "ladder questions", where persons are asked to rank themselves with regard to economic and power status, both for now and before the violence. ${ }^{8}$ The scale ranges from 1 to 9 , with 9 indicating "richest" or "most powerful", respectively. How does past status relate to current status? For example, were those at the bottom of the economic or power scale today also at the bottom in 1999? Investigating this issue requires linking information on the 1999 status with the current assessment. This can be most conveniently done with the help of transition matrices. They capture "intra-distributional" dynamics, and reveal differences in upward and downward mobility. More formally, let

$$
P^{w}=\left[p_{i j}^{w}\right]
$$

be a quadratic transition matrix of order $K$ capturing the change in economic status. States are ranked from worst to best, and the top four steps are collapsed into one state, reducing the number of steps from nine to five. For example, element $p_{12}^{w}$ refers to the probability that an individual at the lowest step in 1999 progresses one step in 2001. Denote by $F_{1999}^{w}$ and $F_{2001}^{p}$ the 1999 and 2001 density functions of economic status, represented as column vectors with five elements. The transition matrix $P^{w}$ satisfies $F_{2001}^{w^{\prime}}=F_{1999}^{w^{\prime}} P^{w}$ where each row adds up to unity $\left(P^{w} 1=1\right)$.

How does one interpret these matrices of $K^{2}$ transition probabilities? Similar to poverty and inequality measurements, various approaches have been developed to analysis the structure of mobility as captured by transition matrices (Bartholomew (1982)). The simplest indicators are scalar summary measures of overall mobility, like the immobility measure $I_{k}$, which gives the share of individuals jumping less than $k$ number of steps, ${ }^{9}$ or the jump measure $J_{s}$, which equals the absolute value of the average step change between 1999 and 2001, to be calculated for each state $s$ and the transition matrix as a whole. Such measures treat upward and downward changes symmetrically, even though higher steps are preferred to lower steps. By contrast, the upward mobility measure $U_{s}$ gives the value of the average step at 2001, again calculated for each row and the matrix as a whole.

\footnotetext{
8 In a series of papers, Ravallion and Lokshin (Ravallion and Lokshin (2001), Ravallion and Lokshin (2002), and Lokshin and Ravallion (2002)) have analysed identical ladder questions using Russian household survey data.

$9 \mathrm{k}$ is no larger than the maximum number of states minus one. is linked to the Shorrocks axiom for transition matrices (Shorrocks (1978)): shifting probability mass from the diagonals to off-diagonals increases mobility.
} 
A transition matrix is "monotone" if a higher step can be obtained from a lower step by moving probability mass to the right (Conlisk (1990)). In other words, it stochastically first-order dominates the distribution represented at a lower step. This property is important in the current context, where states are ranked from worst to best: a monotone matrix preserves the disadvantage of originating from a low state into the future. Finally, I can compare the two transition matrices in terms of their upward-mobility assuming that the mobility structure as characterized by the matrix is constant over time. By multiplying $P$ with itself sufficiently often, it converges to a unique equilibrium probability vector $e$ regardless of the initial distribution. ${ }^{10}$

\subsection{Results}

How has life changed since 1999 in the people's own assessment? The TLSS asked people to assess the changes from 1999 to 2001. Table 1 displays the responses to "ladder questions" of individuals aged 15 years or older, where persons are asked to rank themselves on one of nine steps with regard to economic and power status, both for 2001 and in recall for 1999. Looking back to 1999, the vast majority viewed themselves as poor: about one third of the respondents believed they were on the lowest step, another third on the second lowest step, and another 30 percent between the third to fifth lowest steps. Less than two percent ranked themselves on the top four steps. By comparison, the situation in 2001 is improved, especially for the lowest third. The share of the lowest step decreased significantly, boosting the shares of the second and third lowest steps, with the rest remaining unchanged. Overall, the economic situation of the lowest two thirds improved or remained unchanged, while the one for the highest third remained broadly unchanged. ${ }^{11}$

The responses on power reveal a dramatic shift. In 1999, the bulk of the population viewed itself as powerless, with six in ten placing themselves on the lowest step, and another one in five on the second lowest step. Essentially nobody ranked herself on the top four steps. The situation in 2001 was fundamentally improved. Only one in 20 people in Timor Leste believe they were completely powerless, and close to three in ten ranked themselves on the top

\footnotetext{
${ }^{10}$ More technically, $P$ be the time-invariant mapping of a first-order Markov chain, such that with $t_{2}>t_{1}$. Under certain regularity conditions, there exists an unique "ergodic" equilibrium distribution $\mathrm{p}$ which is the unique solution to $e^{\prime}=e^{\prime} P$ where the components of $e$ add up to unity (Quah (1993) and Kremer et al. (2001)).

${ }^{11}$ Assuming that the means of the two distributions are unchanged, I can apply the concept of first-order stochastic dominance. The 2001 cumulative density function is not higher than the one for 1999 up to the 95 percentile, and therefore first-order dominates the 1999 distribution up to this percentile.
} 
five steps. ${ }^{12}$ These numbers suggest that economic status improved primarily at the bottom tail, while advances in empowerment affected almost the entire population.

The transition matrices for welfare and power are shown in Table 2 and Table 3. ${ }^{13}$ For example, equals 39 percent, indicating that about 4 in ten person who belonged to the lowest step in 1999 moved to the second lowest step in 2001. The corresponding number for power status is 22 percent.

The values for mobility measures are shown in Table 4. Summing over the entries on the main diagonal, I find substantial mobility. Only four in ten persons remain on the step for welfare, and only less than three in ten for power. The other immobility indicators also suggest lower mobility with regard to economic status than power status. The same holds overall for the jump measures, even though those for the top highest steps are lower for power status than for economic status. For the entire matrix, economic status changes on average by half a step, compared to 0.7 steps for power status.

From the perspective of social welfare, more important than overall mobility is upward mobility. For welfare, the average state rank in 2001 is 2.76, compared to the average state rank of 3 , suggesting an overall downward movement. However, in contrast to the top three states, the two lowest states show upward mobility. By contrast, the average state rank in 2001 is 3.86, implying upward mobility. In particular, the improvement at the lowest rank is dramatic, with an average step rank of 3.47. I also find that both transition matrices are monotone so that the disadvantage of originating from a low state is preserved into the future.

The equilibrium vectors, deriving from a first-order Markov chain, are shown in Table 4. The distribution on welfare shows the bulk of the population on the second and third step, and no more than 4 percent on the top step. By contrast, close to two thirds of the population end up on the top ladder for power. Furthermore, the power status equilibrium distribution first-order dominates the one for economic status. This confirms the previous conclusions: on the one hand, the economic situation improved primarily for the poorest families; on the other hand, the population feels broadly empowered as a result of the changes since 1999.

\footnotetext{
12 The 2001 cumulative density function is not higher than the 1999 cumulative density function over the entire range, and therefore first-order dominates the 1999 distribution over the entire range.

${ }^{13}$ About 99 percent of the individuals place themselves on the bottom five steps in terms of welfare in 2001. To facilitate comparability for the empirical analysis, the 9 -step ladder is collapsed into a 5 -step ladder for both welfare and power. The main implication is the underestimation of the power gains. The share of individuals on step 6 or higher increases from 1 percent in 1999 to 14 percent in 2001 .
} 


\section{Welfare and power in 2001}

\subsection{Methodology}

Welfare and power have economic, demographic, social and cultural origins. How can one disentangle the impact of these factors? I follow the standard approach of conducting a multivariate analysis of the determinants of welfare and power. It is analogous to the estimation of cost functions derived from demand behaviour in the literature on consumption estimation (Deaton (1992)). Following Lokshin and Ravallion (2002), I will investigate to what extent self-rated economic welfare and empowerment are related to a common set of covariates. The analysis reveals whether welfare and power share the same determinants, or whether some influences have differential or even opposite impacts. I will go beyond standard economic factors to include social resources. This allows me to separate more carefully the influence of likely correlates of welfare and power.

Accounting for community characteristics is important in order to purge personal and household level factors from community influences. Furthermore, an important theme of the literature on self-rated welfare and happiness is the influence of reference groups. There is evidence that individuals form perceptions about their own circumstances relative to some reference group (Easterlin (1974), Oswald (1997), Ravallion and Lokshin (2002), Hayo and Seifert (2001) and Graham and Pettinato (2001)). Community characteristics can be thought of capturing living standards of such a reference group. ${ }^{14}$

It is useful to formulize the approach in order to spell out more clearly the hypotheses. The basic idea is to specify a reduced form regression of the determinants of welfare and power ( $w$ and $p$ ). I assume that $w$ and $p$ are continuous variables related to observable variables $x$ and unobservable factors, which are represented by independent and identically normally distributed error terms and $u_{i}^{w}$ and $u_{i}^{p}$. The empirical model of the level regressions for 2001 becomes:

$$
\begin{gathered}
w_{i, 01}=\beta_{w}^{b} x_{i, 01}^{b}+\beta_{w}^{e} x_{i, 01}^{e}+\beta_{w}^{s} x_{i, 01}^{s}+\beta_{w}^{c} x_{i, 01}^{c}+u_{i, 01}^{w} \\
p_{i, 01}=\beta_{p}^{b} x_{i, 01}^{b}+\beta_{p}^{e} x_{i, 01}^{e}+\beta_{p}^{s} x_{i, 01}^{s}+\beta_{p}^{c} x_{i, 01}^{c}+u_{i, 01}^{p}
\end{gathered}
$$

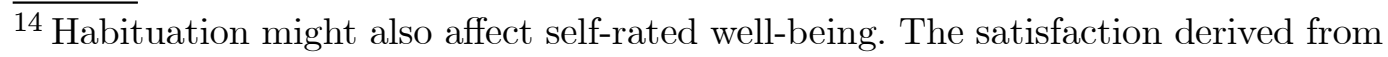
current living standards depends on recent experiences, such that improvements in material endowments triggers a rise in expectations (Brickman and Campbell (1971)). As the assessments are made at the same point in time, habituation is unlikely to be relevant for this analysis.
} 
where individuals $i$ with $w<a_{1}$ will respond to be on the lowest rung of the economic ladder, and those with $a_{1}<w<a_{2}$ to be on the second lowest rung, and so on until the highest rung. Similarly, individuals with $p<b_{1}$ will respond to be on the lowest rung of the power ladder, and those with $b_{1}<p<b_{2}$ to be on the second lowest rung, and so on until the highest rung.

Given the assumption of the distribution of the error terms, I can use ordered probit estimation for the empirical implementation. It preserves all variation in the dependent variables without imposing linearity on the underlying relationship between the explanatory and dependent variables. The regressions show four sets of determinants associated with being "rich" and "powerful" in 2001: basic education and demographic characteristics $b$, economic indicators $e$, social capital $s$, and community infrastructure $c$. The generic hypotheses are that economic resources raise primarily welfare, and social resources raise primarily power.

Hypothesis 1 Economic resources increase welfare:

$$
\frac{\partial w_{i, 01}}{\partial x_{i, 01}^{e}}>0
$$

Hypothesis $\mathbf{2}$ Social resources increase power:

$$
\frac{\partial p_{i, 01}}{\partial x_{i, 01}^{s}}>0
$$

Hypothesis 3 Economic resources increase welfare more than power, and social resources increase power more than welfare:

$$
\frac{\partial w_{i, 01}}{\partial x_{i, 01}^{e}}>\frac{\partial p_{i, 01}}{\partial x_{i, 01}^{e}} ; \frac{\partial p_{i, 01}}{\partial x_{i, 01}^{p}}>\frac{\partial w_{i, 01}}{\partial x_{i, 01}^{p}} .
$$

As is well known, the interpretation of ordered probit regressions is complicated for a number of reasons. The coefficients of ordered probits provide only a clear indication of the marginal probabilities for only the bottom and top categories (Greene (2000)). Further, the magnitude of the change in the outcome probability of a given change in one of the independent variables depends on the levels of all independent variables (Long and Freese (2003)). Finally, ordered probit coefficients are normalized by the unknown variance of their residual variation (Allison (1999)). Differences of welfare and power coefficients might therefore be due to differences in residual variation rather than the impact of control variables. Simple comparisons of ordered probit coefficients between welfare and power estimations presume that the standard deviation of the residual is identical for both regression. ${ }^{15}$

\footnotetext{
${ }^{15}$ However, the scaling due to the unknown variance affects all coefficients equally
} 
The estimation strategy addresses these issues as follows. First, in addition to reporting coefficients, I calculate the marginal effects on the bottom four steps for each of the independent variables, where variables are evaluated at the mean. ${ }^{16}$ Second, when comparing the effect of a covariate on welfare and power, I examine significance levels across the two regressions. Finally, assuming that ladder steps represent cardinal (rather than ordinal) rankings, I run OLS regressions on welfare and power. The estimated threshold values of the ordered probit model give an indication whether the rungs are equally spaced. OLS estimation allows me to explicitly test equality across the coefficients from welfare and power regressions. ${ }^{17}$

\subsection{Covariates}

This section explains the choice of the $\left(x^{b}, x^{e}, x^{s}, x^{c}\right)$ vectors. The empirical analysis is obviously limited to factors that are measured in the TLSS and the village census. These surveys covered economic variables more extensively than measures of social capital. Nevertheless, it includes a number of proxies of empowerment. Since such measures are not typically covered in standard economic analysis, it is useful to review them briefly.

First, important elements of empowerment are inclusion in decision making. ${ }^{18}$ Language is a key vehicle for this dimension. Timor-Leste has an ethnolinguistically diverse population, with more than 30 languages or dialects in use. Timor-Leste adopted Tetun and Portuguese as official languages. While four in five individuals speak Tetun, it is the mother tongue of just over one in ten persons. As a local indicator of social inclusion, I will include a binary variable for having the same mother tongue as the most common mother tongue spoken in the sub-district. ${ }^{19}$

Other indicactors are likely to correlate with social inclusion. Speaking Por-

and can therefore not account both parts of Hypothesis 3 at the same time. See also Footnote 17.

${ }^{16}$ In the case of binary and categorical variables, the marginal effects respond, unless otherwise indicated, to a discrete change from 0 to 1.

${ }^{17}$ An alternative approach would be to restate Hypothesis 3 in terms of the ratio of economic and social coefficients (for example, the differential impact on welfare to power of unemployment relative to mother tongue Tetun), as this eliminates the unknown variance of the ordered probit estimation (Hoetker (2001)).

${ }^{18}$ World Bank (2002b) identifies four key elements of empowerment: inclusion/participation, access to information, local organizational capacity, and accountability.

${ }^{19}$ Ross and Mirowsky (1992) find evidence for the US that minority groups have less sense of control over their lives. 
tuguese signals inclusion, but it also reflects high human capital. Similarly, education raises returns to economic acitivity but it also enables people to access and process information more effectively. Men are typically the main bread winners in households but being male might also indicate a greater involvement in community decisions. ${ }^{20}$ It will be important to contrast the impact of these variables with and without controls for economic resources.

Second, access to information is important. Informed citizens are better able to access services, exercise their rights, and hold others responsible. The number of radios or television sets owned by the household is a crude proxy for this dimension.

Third, empowerment is linked to local organizational capacity. Well-mobilized groups are more likely to have their voices heard and to solve common problems. ${ }^{21}$ The TLSS includes information about participation in user groups over the last 12 months.

Finally, accountability of community leaders is another component to empowerment. The surveys do not include direct measures on the responsiveness of village and hamlet chiefs to the concerns of the population. However, the village census provides information on the education status and number of years lived in the village of the village leaders.

To summarize, these variables will serve as indicators of high social resources: having mother tongue Tetun; speaking the most common mother tongue in the sub-district as mother tongue; ownership of radios and television sets; participation in user groups; and village leaders with large human capital and life span in the village.

To facilitate the interpretation of the results, variables are, whenever possible, represented through a single index. ${ }^{22}$ For example, education is represented as a single variable, ranging from 0 of no schooling to 4 for post-lower secondary education. Monetary economic variables, like consumption and assets, are given as per capita Rupiah values. ${ }^{23}$ Housing is represented by the prin-

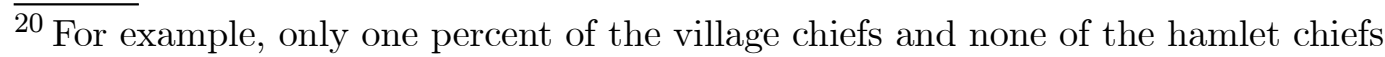
interviewed for the village census were women.

${ }^{21}$ Inman and Oberholzer-Gee (2003) uncover evidence for the US that democratic institutions which permit citizens to actively shape policies foster a sense of control and self-esteem.

${ }^{22}$ As the ordering of occupational groups is not self-evident, each category is included separately (unemployed, non-coffee farmer, coffee farmer, pensioner, student, and wage earner).

${ }^{23}$ Nominal values are deflated over time and space. The value of 10,000 Rupiah is about US $\$ 1$.
} 
cipal rotated factor from factor analysis. ${ }^{24}$

Following equations 2 to 5, the determinants are grouped into four categories.

- Basic characteristics $x^{b}$ : demographics including gender, age, and age squared of the individual; household size (number of persons) and the share of individuals in these age groups (under 6, 7-14, 15 - 49 (omitted category), and 50 plus); marital status (married or single with widow/widower as omitted category); education (index ranging from 0 to 4 (no schooling (omitted category), lower primary (year $1-3$ ), upper primary (year $4-6$ ), lower secondary, and post-lower secondary (including university))); parental schooling indicator (equal to one if either father or mother or both went to school).

- Economic characteristics $x^{e}$ : Housing conditions (index of type of dwelling, floor area, drinking water, electricity, and sanitation derived using factor analysis); per capita value of assets as the sum of estimated values of land, livestock, and savings; ${ }^{25}$ six occupation categories (unemployed, non-coffee farmer, coffee farmer, pensioner, student, and wage earner (omitted category); monthly per capita aid assistance during the last 12 months; ${ }^{26}$ access indicator of dwelling to paved road (equals to 1 if no access during rainy season; 2 if access with more than 10 minutes distance; 3 if access with between 5 to 10 minutes distance; and 4 if access with less than 5 minutes distance); welfare ratio (per capita value of consumption during the last month relative to the poverty line); ${ }^{27}$ and non-household Aldeia average of the welfare ratio.

- Social characteristics $x^{s}$ : User group (share of adult household members participating in community groups during the last 12 months); number of radios or television sets owned by the household; indicator variables for the four most common mother tongues (Bunak, Macasae, Mambae, and Tetun, with other mother tongues as omitted category); indicator variables for speaking Tetun and Portuguese; an indicator variable for having the mother tongue that is the most prevalent in the sub-district; and the average

\footnotetext{
${ }^{24}$ The results are unchanged if the housing index is replaced by the estimated rental value of housing.

${ }^{25}$ Land value is based on the household's estimated sales value of land. Livestock value is the sum of young and old livestock (buffalo, bali cow, cow, horse, pig goat, sheep, chicken, other) evaluated at the median price estimate of farmers. Savings is the sum of cash holdings in Rupiah and foreign currency, deposits with Indonesian banks or other institutions, gold, silver or other precious metals, and jewellery.

${ }^{26}$ Aid assistance is the sum of the estimated value of 19 items (credit/cash, vaccination for livestock, cattle, pigs, chicken, seeds, fertilizers, fruit trees, agricultural tools, non-agricultural tools, fishing nets, mosquito nets, mosquito net repair kits, contraception, housing repair kits, building materials, rice, corn, and other food) received over the last 12 months from NGOs, the church, or other organizations.

27 The derivation of the consumption measure and poverty line is discussed in detail in World Bank (2003).
} 
number of years of education of the village leaders, and the average number of years lived in the village by the village leaders.

- Community infrastructure $x^{c}$ : Hamlet infrastructure as sum of twelve indicator variables on facilities (primary school, secondary school, health centre, church, kiosk, shop, everyday market, periodic market, bank, mill, vehicle passable road, and paved road); hamlet indicator for piper water supply; village level teacher-student ratio; village level classroom-student ratio; village level monthly days of health services per capita; village income sources (number of major village income sources, ranging from 1 to 3 ); village indicators for type of most important income source (rice or maize (omitted category), coffee, and other); and indicator variables on five geographical strata (capital Dili (omitted category), other urban, rural west, rural center, and rural east).

\subsection{Specification}

Table 5 presents three models for welfare and power in 2001 as dependent variables. The estimation model is build around standard determinants of consumption or income regressions, complemented by social and community variables. The first model includes basic, social and community characteristics (columns 1 and 4 of Table 5). The second model adds economic indicators (columns 2 and 5). The inclusion of economic controls purges education, household size, and community and regional-level factors of some economic variation within and across household clusters. The coefficients of most original variables remain broadly unchanged.

The evidence for reference group effects is stronger for welfare than power. Out of the 12 village, hamlet and capital variables, 8 have negative coefficients for welfare, and 6 for power. Model 3 (columns 3 and 6) adds the welfare ratio, defined as monthly per capita expenditures normalized by the poverty line, and the village welfare ratio (excluding the household's value) as regressors, and drops community variables and regional dummies instead. ${ }^{28}$ The welfare ratio enters positively and significantly, indicating that welfare and, to a lesser extent, power rise with objective economic well-being, and the coefficients of other variables change little. The coefficient on the village welfare ratio is negative for welfare and positive for power, and insignificant in both cases. ${ }^{29}$ This could imply either the absence of strong reference group effects or that

$\overline{28}$ This model clearly has potential endogeneity problems, as the welfare ratio is likely to be correlated to omitted determinants of economic well-being. At the same time, as argued in Ravallion and Lokshin (2002), it is difficult to think of instruments for the welfare ratio that would not be correlated with the error term.

${ }^{29}$ McBride (2001) finds for US data that reference group effects may be smaller at low income levels. 
community infrastructure variables are better proxies of the living standards of reference groups. ${ }^{30}$

I will now turn to a more detailed discussion of the estimation of Model 2. Following Ravallion and Lokshin (2002), the Aldrich-Nelson Pseudo $R^{2}$, corrected according to Veall and Zimmermann (1996), is used to measure overall fit. While the overall fit of the welfare regressions is higher than the one of the power regressions, the top panel of Table 6 shows that the model does well in predicting the overall shares of the step categories for both welfare and power (rows 1 to 4 ). Table 6 also displays the predicted probabilities for two key binary economic and social variables: wage earner (versus being unemployed) and mother tongue Tetun (versus having none of the four most common local languages as mother tongue). Being wage earner is associated with high welfare rungs (Row 7), confirming Hypothesis 1, and mother tongue Tetun is associated with high power rungs (Row 16), consistent with Hypothesis 2. By contrast, wage earners are on lower power rungs than the unemployed (Row 13, and native Tetun speakers are on lower welfare rungs than those with other mother tongues (Row 10). As a result, relative to the power distribution, being wage earners decreases the probability mass on the low rungs (Row 17), and mother tongue Tetun increases the probability mass on the low rungs (Row 18), in line with Hypothesis $2 .{ }^{31}$

Table 7 shows the marginal effects for the bottom four steps of all independent variables. The estimated threshold values of Model 2 in Table 6 are consistent with a linear specification. Table 7 displays the OLS estimation of Model 2 (columns 6 to 7 and 12 to 13) and the p-values of F-tests for equality of parameters between the welfare and power models (Column 14).

\subsection{Welfare}

This section will dicuss the estimation results for welfare and power in 2001 of Model 2. It discusses first the basic characteristics, and then moves on to economic and social features.

\footnotetext{
${ }^{30}$ Defining the reference group at the hamlet rather than village level leads to smaller (closer to zero) and less significant coefficients. In contrast to ?, there is no evidence that inequality matters for self-assessed well-being. Quintile indicators, which account for the households position within the consumption distribution either for the population as a whole or specific to the individual's language group, are insignificant.

31 The 6 th to 9 th rungs of the power distribution are merged into one single rung for the comparison with the welfare distribution in rows 17 and 18 .
} 


\subsubsection{Basic characteristics}

In Timor-Leste, cultural values in family and social life are influenced by catholic beliefs. As in most countries in the world, women have traditionally the primary responsibility for housework and the upbringing of children. Men have assumed the main responsibility in resource allocation and investment decisions both in the household and in the community. In the bivariate setting, being male is associated with slightly higher welfare. However, once controlled for basic characteristics, the correlation reverses and the coefficient is insignificant.

Welfare is positively associated with age for the bulk of the age range. It peaks at the age of 67 , at the 97 th percentile of the age distribution. ${ }^{32}$ One in six women aged 15 years and older are widows. Elderly women are widows primarily due to higher female than male life expectancy ( 58 years versus 54 years), whereas many younger women have lost their husbands as a result of the conflict with Indonesia. Widowhood can affect the physical safety, identity and mobility of women and children, their access to basic goods and services necessary for survival, and their rights to inheritance, land and property. The regression confirms that widows and widowers have lower welfare than either single or married persons. ${ }^{33}$

Larger households benefit from economies of scales. Holding per capita levels of economic variables constant, larger household size is associated with higher subjective welfare. Replacing a prime-age adult with children or elderly tends to reduce welfare.

Education is not just critical for productive employment and economic growth, but also instrumental for accessing and disseminating information and participating in community life. More than one in two adults have no schooling whatsoever, and only one in seven have more than lower secondary education. Education is positively associated with welfare. About one in 14 individuals aged 15 or older have at least one parent who went to school. ${ }^{34}$ Parental education has a positive and significant impact on welfare.

\footnotetext{
${ }^{32}$ This contrasts to evidence from developed countries of a U-shaped relationship between happiness and age (Blanchflower and Oswald (2000)).

${ }^{33}$ Using British household data from 1991 to 1997, Clark and Oswald (2002) find that widowhood brings a degree of unhappiness that would take on average an extra 170,000 pounds per annum to offset.

${ }^{34}$ Educational attainments of the parent generation is abysmally low, a legacy of the Portuguese colonial period up to 1975. The percentage of individuals without primary education rises from 61 percent for those aged 33 to 42 years, to 81 percent for those aged 43 to 52 years, and to 92 percent for those 53 years or older.
} 


\subsubsection{Economic characteristics}

The evidence supports Hypothesis 1: economic resources raise welfare. Assets are an insurance against economic uncertainty and a way for preparing for future expenses. They are held primarily in the form of housing, land and livestock. Land is the most important factor of production in agriculture, the primary source of income for three quarters of the population. ${ }^{35}$ Nine in ten rural dwellers live in households that own animals. Cattle, pigs, chicken and other animals are life-enhancing and life-supporting, feeding both people and soils. ${ }^{36}$ The household's access to markets and institutions is often proxied by distance variables. ${ }^{37}$ Timor-Leste reached a modest degree of financial mediation during Indonesian times. With the 1999 crisis, the financial system came to a complete halt, and the de-facto prohibition to access Indonesian deposits. As a result, in today's economy, most families get by without reliance on financial assets. ${ }^{38}$ Assets per capita, derived as the total value of land, livestock, and savings, are highly significantly and positively associated with welfare. Decent housing conditions and close proximity to a paved road increase welfare. ${ }^{39}$ Finally, about three in ten individuals receive some form of aid assistance during the last 12 months. It is positively associated with welfare.

Welfare varies among occupation groups consistently with expectations. About

$\overline{{ }^{35} \text { Land }}$ access is determined by a traditional system of land tenure. Households claim to own 95 percent of the land under their control. The size of the land holdings is small: the average area per person is 0.4 hectares, the median area per person is only 0.22 hectares, and fewer than one in twenty persons with land access hold more than one hectare per capita. The quality of the land varies - about one fifth is irrigated and less than two-fifths are flat.

36 The value of livestock assets is about US\$100 per capita, which amounts to four times the monthly per capita expenditures. About one in ten persons in rural areas have per capita livestock holdings in excess of US $\$ 200$.

37 There were seven commercial banks, one development bank, a branch office of the Central Bank, six insurance companies and one exchange bureau. In September 1999, broad money was 28 percent of GDP, amounting to about US $\$ 100$ million.

${ }^{38}$ About one in two persons live in households without any financial wealth. For savers, these assets amount on average to 140 percent of their monthly expenditures, but the median is only as high as a third of that. Overall, slightly more than three fifth of the financial assets is held in broad money (cash or deposits). The most widespread form of savings comes in Rupiah cash holdings, followed by jewelry and foreign cash holdings (mostly US Dollars). About one quarter of total savings is held in Rupiah cash, another quarter in foreign currency, another fifth in precious metals, like gold and silver, and another fifth in jewelry. Only one in 25 persons live in households with deposits at Indonesian institutions, which represent one seventh of total savings.

39 The results are very similar if the estimated rental value of housing is included instead of the housing index. 
8 percent of the individuals aged 15 years and older are unemployed, 30 percent work as subsistence farmers, 12 percent as coffee farmers, 29 percent are pensioners, 13 percent are students, and 8 percent receive salaries. The unemployed have the lowest self-rated welfare, ${ }^{40}$ followed by subsistence farmers. Coffee farmers, who produce one of the few cash crops and export products in Timor-Leste, are better-off. Salaried workers (omitted group), including civil servants, teachers and traders, and students have the highest welfare.

\subsubsection{Social characteristics}

There are opposite signs of the coefficients for Tetun as mother tongue versus speaking Tetun. Having Tetun as mother tongue lowers welfare, while being able to speak Tetun raises welfare. Speaking the national language provides economic benefits, even if it is not the mother tongue, or is a proxy for unobserved human capital. Similarly, speaking Portuguese, as done by about one in twenty adults, raises welfare.

Bunak, the native language of about 10 percent of the population who are primarily concentrated in the western part of the country, is associated with higher welfare. By contrast, Macasae, the native language of people in the East, is related to lower levels of welfare. The impact of mother tongue on welfare could reflect aspects of social cohesion and social exclusion of ethnic groups to the extent that these factors influence perceived economic wellbeing. About seven in ten persons share the most common mother tongue in the sub-district. The coefficient is positive and significant, suggestive of a positive impact of social inclusion on welfare.

Just over four in ten individuals live in households with either radio or television sets. The coefficient is positive and significant in Model 1, but becomes insignificant in Model 2 and Model 3, once economic control variables are added. This suggest that owning radios and television sets raise welfare as correlates of wealth but not as proxies of information. Participation in user groups, or educated village leaders with a long life span in the village has no positive impact on welfare.

\subsubsection{Community characteristics}

There is no consistent pattern for the signs of community variables. Economic characteristics, such as the number of village income sources and coffee growing area lower welfare (consistent with the reference group effect), whereas piped water access raises welfare (consistent with a positive impact of infrastructure

\footnotetext{
${ }^{40}$ This confirms results on industrialized countries (Ravallion and Lokshin (2002), Oswald (1997), and Winkelmann and Winkelmann (1998)).
} 
on living standards). Relative to the major urban areas of Dili and Baucau, welfare is higher in other urban areas and rural center, and lower in rural east.

\subsection{Power}

What are the determinants of power? Do they differ from those of welfare? The discussion will focus on the evidence with regard to hypotheses 2 and 3. ${ }^{41}$

- Hypothesis 2: Social resources, indicated by mother tongue Tetun (but not speaking Tetun), having the principal sub-district language as mother tongue, ${ }^{42}$ ownership of radios and televation sets, participating in village groups, ${ }^{43}$ and educated village leaders who lived many years in the village, raise power.

- Hypothesis 3: Economic factors raise welfare more than power, ${ }^{44}$ while social factors raise power more than welfare. Housing, assets, and aid assistance have a positive sign and are at least marginally significant in the power regression, but the coefficients are smaller than in the welfare regression. The coefficient on paved road is positive and insignificant, and smaller than for welfare. Non-coffee farmers are worse off than wage earners, while there are no significant difference among other occupational groups. The coefficients on welfare ratio (in Model 3) and parental schooling are positive and smaller than the corresponding coefficients for welfare. ${ }^{45}$ Turning to social factors, mother tongue Tetun increases power but lowers welfare, while speaking Tetun benefits power less than welfare. Ownership of radios and television sets increases power but not welfare. Attending a community group raises power but not welfare. Power, but not welfare, is strongly positively correlated to education levels and years spent in the locality of community leaders. ${ }^{46}$

\footnotetext{
${ }^{41}$ The results are very similar if the four highest steps are aggregated into one step in line with the number of categories for welfare.

${ }^{42}$ Consistent with this pattern, the coefficients on the four main mothers tongues in Timor-Leste are positive in Model 3 when regional and community infrastruction variables are dropped.

${ }^{43}$ Participation in village groups is only in some specifications marginally significant. ${ }^{44}$ Focusing on individual and household income, Lokshin and Ravallion (2002) find a similar pattern for Russia.

${ }^{45} \mathrm{~F}$-tests using the OLS regressions of welfare and power reject the null hypothesis of equality of coefficients for household assets, paved road and unemployment at the 5-percent significance level (Column 14 of Table 7).

46 The null hypothesis of equality of coefficients is rejected for mother tongue Tetun, ownership of radios and television sets, education, and village leader characteristics at the 5-percent significance level (Column 14 of Table 7).
} 
Turning to other variables, coefficients on demographic characteristics are smaller than for welfare. Men have more power than women, and older men more power than young men, but the coefficients are insignificant. The coefficient on household size is positive but smaller than for welfare, while replacing working age adults with young children reduces power but not welfare. Education increases power more than welfare once controls for economic factors are included.

\section{Changes in welfare and power}

\subsection{Methodology}

The framework of Section 4.1 can be extended to shed light on the determinants of changes in welfare and power from 1999 to 2001. The objective is to identify the winners and losers of the fundamental transformation over this period. Following Glewwe and Hall (1998), I will address this issue from the perspective of the intial characteristics (as of 1999 before the violence). Focusing on variables that are either time-invariant (like gender, age, or education for adults) or predetermined (measured as of before the violence) is useful for two reasons. It avoids the econometric pitfall of downward bias of endogenous variables, ${ }^{47}$ and allows me to interpret the coefficients in terms of reduced form, incorporating the effect of endogenous responses to the structural changes.

In addition, the violence did not affect all individuals equally. To capture some of this heterogeneity, I will augment the specification with shock and changes variables that measure the exposure to the violence of 1999, the receipt of aid assistance, and changes in health, corruption and sectors. The underlying assumption is that these factors are broadly outside the individual's control.

In view of these considerations, the specifications for the change regressions are as follows: ${ }^{48}$

\footnotetext{
${ }^{47}$ If time-variant regressors are correlated with unobserved factors captured in the error term, then the coefficients of the time-variant regressors will be downward biased (Glewwe and Hall (1998)).

48 The point estimates of equations 4 and 5 are identical to the differences of separate level regressions of 1999 and 2001 (subsuming the shock under 2001). However, estimating difference regressions is more efficient as it removes any individual-specific fixed-effects like risk aversion (Glewwe and Hall (1998)) or personal character traits (Diener et al. (1999) and Ravallion and Lokshin (2001)).
} 


$$
\begin{gathered}
\Delta w_{i}=\gamma_{w}^{v} z_{i}^{v}+\Delta \gamma_{w}^{b 1} z_{i, 99}^{b}+\Delta \gamma_{w}^{b 2} z_{i, .}^{b}+\Delta \gamma_{w}^{e} z_{i, 99}^{e}+\Delta \gamma_{w}^{s} z_{i, .}^{s}+\Delta \gamma_{w}^{c} z_{i, .}^{c}+\Delta u_{i}^{w} \\
\Delta p_{i}=\gamma_{p}^{v} z_{i}^{v}+\Delta \gamma_{p}^{b 1} z_{i, 99}^{b}+\Delta \gamma_{p}^{b 2} z_{i, .}^{b}+\Delta \gamma_{p}^{e} z_{i, 99}^{e}+\Delta \gamma_{p}^{s} z_{i, .}^{s}+\Delta \gamma_{p}^{c} z_{i, .}^{c}+\Delta u_{i}^{p}
\end{gathered}
$$

where $\Delta w_{i}=w_{i, 01}-w_{i, 99}, \Delta p_{i}=p_{i, 01}-p_{i, 99}$, and $\Delta u_{i}=u_{i, 01}-u_{i, 99}$. These regressions characterize which individuals, in terms of initial condition and shock exposure, became "richer" and "more powerful" between mid-1999 to end 2001. The right-hand side variables differ to equations 2 and 3 in five regards. First, $v$ represents exposure to shocks and changes since 1999. Second, in addition to distinguishing explanatory factors according to type of characteristic (violence $v$, basic $b$, economic $e$, social $s$, and community $c$ ), variables are indexed with regard to being time-invariant (indicated by subscript ".") and pre-determined (indicated by subscript "99"). As discussed below, in addition to the shock measures $z_{i}^{v}$, the estimation includes pre-determined basic $\left(z_{i, 99}^{b 1}\right)$ and economic $\left(z_{i, 99}^{e}\right)$ variables, and time-invariant basic $\left(z_{i, .}^{b 2}\right)$, social $\left(z_{i, .}^{s}\right)$, and community $\left(z_{i,}^{c}\right)$ variables. Third, the TLSS does not provide complete recall information on all time-varying $x$ variables of equations 2 and 3 . The $z$ variables in equations 4 and 5 are therefore typically a subset of the $x$ variables of equations 2 and 3 . Fourth, the random errors $u_{i, 01}$ and $u_{i, 99}$ are differenced, which may reduce correlation with them and the observable determinants. ${ }^{49}$ Fifth, equations 4 and 5 give direct estimates of the changes in the coefficients from 1999 to 2001. They indicate whether the fundamental transformation led to an increase $(\Delta \gamma>0)$ or decrease $(\Delta \gamma<0)$ in the returns to characteristics. Individuals with high values of a characteristic for which $\Delta \gamma$ is positive (negative) are winners (losers) of the systemic changes since the referendum on independence.

As before, the discussion of the estimation results will be guided by hypotheses on Timor-Leste's recent history. The analysis of Section 3 suggested that welfare gains were highest for individuals who ranked low in 1999.

Hypothesis 4 Welfare winners have low initial economic resources:

$$
\frac{\partial w_{i}}{\partial z_{i, 99}^{e}}<0
$$

By contrast, Section 3 indicated that most population groups benefited from

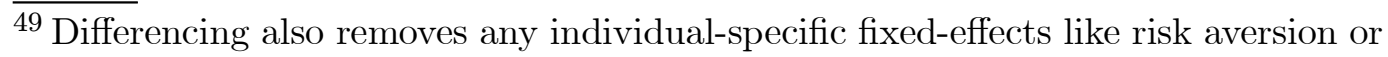
other time-invariant character traits. 
a rise in power. I conjecture that individuals with high social characteristics benefited from stronger empowerment than others.

Hypothesis 5 Power winners have high social resources:

$$
\frac{\partial p_{i}}{\partial z_{i, .}^{s}}>0
$$

Finally, negative economic shocks are expected to lower welfare and power but have a larger impact on welfare than power.

Hypothesis 6 Negative economic shocks lower welfare and power, and welfare more than power:

$$
\frac{\partial w_{i}}{\partial z_{i}^{v}}<\frac{\partial p_{i}}{\partial z_{i}^{v}}<0 \text { for } z^{v} \text { as negative economic shock. }
$$

\subsection{Covariates}

The modified framework of equations 4 and 5 implies a different specification of the $\left(z^{b}, z^{e}, z^{s}, z^{c}, z^{v}\right)$ vectors compared to the level models of equations 2 and 3. Attention is restricted to time-invariant and pre-determined variables and shock or change measures.

- Basic characteristics $z^{b}$ : Gender, age and parental education are time-invariant variables. The TLSS included modules on school enrollment back to 1998/99 and changes in household composition since the violence in 1999, covering members both joining and leaving the household. Using this information, I construct household composition and education levels as before the violence in 1999. About one in five households changed household size during 1999 to 2001, and one in sixteen individuals aged 15 and older underwent schooling since the violence in 1999 .

- Economic characteristics $z^{e}$ : Asset holdings and housing conditions are endogenous and likely to have changed since 1999. Households provided recall information on the levels of livestock holdings in 1999. About one in twenty families had an Indonesian bank account in 1999.

- Social characteristics $z^{s}$ : Ownership of radios and television sets is timevariant, and the displacement since 1999 is likely to have affected the language composition of sub-district populations. Mother tongue is determined at birth, while ability to speak Tetun and Portuguese are unlikely to have changed substantially since 1999 .

- Community characteristics $z^{c}$ : While community infrastructure and leaders characteristics are likely to have changed since 1999, the indicator variables of regions and district and sub-district capitals are time-invariant. 
- Shock variables $z^{v}$ : The impact of the violence is measured both at the household annd village level. The household level variables are: an indicator variable for change in dwelling since the violence (one in five individuals); a categorical variable for housing destruction (equals to 0 for two thirds of the individuals who incurred no destruction, 1 for 6 percent of individuals who incurred partially destruction, and 2 for close to 30 percent of individuals whose houses were totally destroyed); and an indicator variables for loss of livestock (about six in ten individuals live in households who lost livestock). The village level variables are: an indicator variable on destruction of classrooms (10 percent of villages) and another indicator variable on loss of livestock (85 percent of villages). There are three types of change variables: a categorical variable on changes in corruption compared to before the violence (equals to 1 for "more corruption now", 2 for "as much corruption", and 3 for "less corruption"; two in five believe corruption has improved, compared to one in five who believe it has worsened); a categorical variable on changes in own health compared to one year ago (equals to 1 for "worse now", 2 for "as before", and 3 to "better now"; one in four believe health has improved, and one in twenty it has worsened); and a set of ten sectoral change variables, covering education, employment health care, housing, access to land, demand for products, infrastructure, safety, political participation and status in community (equals to 1 for worst deterioration since the violence, 2 for second worst deterioration, 3 for no change, 4 for second largest improvement, and 5 for largest improvement). ${ }^{50}$

\subsection{Specification}

Table 8 show four models. Model 1 includes only time-invariant variables; Model 2 adds pre-determined variables as of before the violence in 1999; Model 3 augments Model 2 with shock variables; and Model 4 includes also the change variables. Since the signs and size of most coefficients are remarkably stable over the specifications, the discussion focuses on Model 4. In contrast to the 2001 regressions, the overall fit for power is higher than for welfare, but the models do well in predicting the overall shares of the rung categories for both variables (rows 1 to 4 of Table 9). The threshold estimates suggest a linear specification, and the OLS regressions are displayed in Table 10, in addition to the marginal effects for the bottom four steps of all independent variables.

The second and third panels of Table 9 look at the evidence on hypotheses 4 to 6 for three variables: bank account in 1999 as economic resource; mother

\footnotetext{
50 The variables are constructed from these two questions: "What has improved since the violence in 1999?"; "What has worsened since the violence in 1999?". Each question allowed for two responses from ten sector categories.
} 
tongue Tetun as social resource; and livestock loss as shock variable. Having a bank account in 1999 is associated with low welfare rungs (Row 7), supporting Hypothesis 4, and mother tongue Tetun is correlated with high power rungs (Row 16), consistent with Hypothesis 5. Livestock loss leads to a drop in welfare (Row 13) and power (Row 22) but the effect is larger on welfare than power (Row 23), in line with Hypothesis $6 .{ }^{51}$

\subsection{Welfare}

Who are the welfare winners and losers in today's population of the fundamental changes since before the referendum for independence (columns 1 to 4 of Table 8)?

- Hypothesis 4: The coeffients on bank acount in 1999 and per capita livestock values in 1999 are negative and significant. Other variables related to economic status confirm this pattern. In Model 1, parental education, arguably a proxy for permanent income, is negative and signifcant. Returns to household size increase over the period, suggesting that welfare winners of the transition included large families who are typically poorer than small families. Indicators for sub-district and district capitals, where infrastructure is likely to be better developed than in other parts of the country, are negative and significant. Education in 1999, age, and speaking Portuguese (as possible proxy for permanent income) are (marginally) insignificant in all specifications.

- Hypothesis 6: Negative economic shocks at the level of households (housing destruction and livestock loss) and villages (classroom destruction and livestock loss) imply a reduction in welfare gains. Resettlement also lowers welfare. Improvements in demand for products, infrastructure, control of corruption, education and own-health lead to higher welfare, while more political participation or a higher status in the community have no impact.

The findings point to these regularities. Individuals with high initial economic status are welfare losers (Hypothesis 4). Individuals who suffered specific losses, like damaged houses, livestock reduction, resettlement, or a decline in health, fared worse than others (Hypothesis 6).

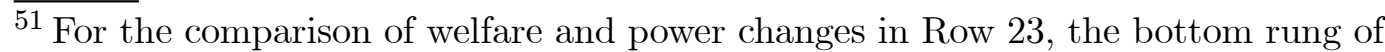
the welfare distribution is merged with the second lowest rung, and the 4th to 7th rungs of the power distribution are merged with the 3rd rung.
} 


\subsection{Power}

How does this evidence contrast with the determinants of power winners (columns 5 to 8 in Table 8$)$ ?

- Hypothesis 5: Returns to mother tongue Tetun rise strongly, while those to speaking Tetun decline. Power returns to education rise more than those for welfare returns, suggesting a greater importance of education for power than welfare. In contrast to welfare changes, the returns to initial economic status increase over time, suggesting that power gains are regressive.

- Hypothesis 6: Negative household and village level shocks generally reduce power, although the coefficients are smaller in absolute terms than for welfare. ${ }^{52}$ Resettlement has a larger impact on power than welfare changes, suggesting that the disruptive effect on social networks outweighs the loss of location-specific economic resources. Improvements in economic sectors leave power unchanged, while more political participation and higher community status raise power, as do less corruption and better own-health. ${ }^{53}$

Overall, the results suggest that power winners include those with strong social resources (Tetun as mother tongue rather than speaking Tetun and no displacement) (Hypothesis 5). Negative economic shocks diminish power but the impact is less than on welfare (Hypothesis 6).

\section{Conclusion}

This paper evaluated changes in well-being in Timor-Leste between 1999 and 2001 , covering the period from prior to the referendum on independence from Indonesia to the eve of independence at the end of 2001. It demonstrated how subjective, objective and recall data from a single cross-sectional survey can be combined to provide a rich characterization of the changes in economic and power status during a time of systemic economic and political transformations.

The mobility analysis established that overall self-rated welfare improved little, while self-rated power increased dramatically. However, the changes were not

\footnotetext{
52 The coefficient on household livestock loss is insignificant and close to zero. However, power changes are negatively correlated to livestock loss in the bivariate setting. Dropping regional controls (area dummies and language variables) from the regression, the coefficient on livestock loss is negative and significant at the 2-percent level.

53 The null hypothesis of equality of coefficients is rejected for demand for products, employment, housing, health care, political participation, status in community and housing destruction at the 10-percent significance level (Column 14 of Table 10).
} 
uniform across the entire population, but some groups benefited more than others. Three features stand out.

First, the 2001 levels of self-rated welfare and power relate to objective indicators consistently with expectations. Assets and occupational status increased welfare and power. Economic characteristics had a stronger impact on selfrated welfare than on self-rated power, while language, access to information, and user group participation had a larger impact on power than on welfare. There is no conclusive evidence on reference group effects.

Second, turning to the economic changes between 1999 to 2001, individuals with low initial economic status were welfare winners, as returns to economic endowments decreased during the transition. This is indicated by negative and significant coefficients on livestock holdings in 1999 and bank accounts in 1999, and sub-district and district capitals, and low and insignificant coefficients on education, parental education, and speaking Portuguese. Further, persons who suffered negative economic shocks, whether at the level of the individual (health), household (livestock, housing), or village (livestock, classrooms), fared worse than others. Similarly, improvement in the economic environment, such as product demand, infrastructure and corruption, increased welfare.

Third, power winners differed from welfare winners. Power winners included individuals with strong social resources (Tetun as mother tongue rather than speaking Tetun, no displacement). Compared to initial economic status, power gains were regressive while welfare gains were progressive. Negative economic shocks diminished power, but the impact was less than on welfare, while improvements in political participation and community status increased power. 


\section{References}

Allison, P. D. (1999). Comparing logit and probit coefficients across groups. Sociological Methods and Research 28.2, 186-208.

Arrow, K. (1950). A difficulty in the concept of social welfare. Journal of Political Economy 58, 328-346.

Bartholomew, D. (1982). Stochastic Models for Social Processes. New York: John Wiley.

Baulch, B. and J. Hoddinott (2000). Economic mobility and poverty dynamics in developing countries. Journal of Development Studies 36.6, 1-24.

Blanchflower, D. and A. Oswald (2000). Well-being over time in Britain and the USA. National Bureau of Economic Research Working Paper 7487.

Brickman, P. and D. Campbell (1971). Hedonic relativism and planning the good society. In M. Apley (Ed.), Adaptation-Level Theory: A Symposium, pp. 287-302. New York: Academic Press.

Browning, M. (1992). Children and household economic behavior. Journal of Economic Literature (30), 1434-75.

Clark, A. and A. Oswald (2002). A simple statistical method for measuring how life events affect happiness. University of Warick, mimeo.

Conlisk, J. (1990). Ranking mobility matrices. Journal of Mathematical Sociology 15, 173-91.

Deaton, A. (1992). Understanding Consumption. Oxford: Clarendon Press.

Deaton, A. (1997). The Analysis of Household Surveys. Washington, DC: World Bank.

Diener, E., E. Suh, R. Lucas, and H. Smith (1999). Subjective Well-Being: Three decades of progress. Psychological Bulletin 125, 276-302.

Easterlin, R. (1974). Does economic growth improve the human lot? Some empirical evidence. In P. David and M. Rider (Eds.), Nations and Households in Economic Growth. Essays in Honor of Moses Abramovitz. New York: Academic Press.

Frey, B. and A. Stutzer (2000). Happiness, economy and institutions. The Economic Journal 110, 918-938.

Glewwe, P. and G. Hall (1998). Are some groups more vulnerable to macroeconomic shocks than others? Hypothesis tests based on panel data from Peru. Journal of Development Economics 56, 181-206.

Graham, C. and S. Pettinato (2001). Frustrated achievers: Winners, losers, and subjective well being in new market economies. The Brookings Institution, Center on Social and Economic Dynamics Working Paper Series 21.

Greene, W. H. (2000). Econometric Analysis. London: Prentice-Hall.

Hayo, B. and W. Seifert (2001). Subjective economic well-being in Eastern Europe. Essen University, mimeo.

Hoetker, G. (2001). Confounded coefficients: Accurately comparing logit and probit coefficients across groups. University of Illinois, mimeo.

Inman, R. and F. Oberholzer-Gee (2003). Democratic institutions and subjective well-being. University of Pennsylvania, mimeo. 
Kremer, M., A. Onatski, and J. Stock (2001). Searching for prosperity. NBER Working Paper 8250.

Lokshin, M. and M. Ravallion (2002). Rich and powerful? Subjective power and welfare in Russia. World Bank Policy Research Working Paper 2854.

Long, J. and J. Freese (2003). Regression Models for Categorical Dependent Variables Using Stata. Texas: Stata Corporation.

McBride, M. (2001). Relative-income effects on subjective well-being in the cross-section. Journal of Economic Behavior and Organization 45, 251-278.

Munoz, J. (2001). Timor Loro Sa'e Living Standards Survey Sampling Design and Implementation. World Bank, mimeo.

Oswald, A. J. (1997). Happiness and economic performance. Economic Journal 107, 1815-1831.

Pollack, R. and T. Wales (1979). Welfare comparison and equivalence scale. American Economic Review 69.2, 216-221.

Quah, D. (1993). Empirical cross-section dynamics in economic growth. European Economic Review 37, 426-434.

Ravallion, M. and M. Lokshin (2001). Identifying welfare effects using subjective questions. Economica 68, 335-357.

Ravallion, M. and M. Lokshin (2002). Self-rated economic welfare in Russia. European Economic Review 46.8, 1453-1473.

Ross, C. and J. Mirowsky (1992). Households, employment and the sense of control. Social Psychology Quarterly 55, 217-35.

Sen, A. (1999). Development as Freedom. Oxford: Oxford University Press.

Shorrocks, A. (1978). The measurement of mobility. Econometrica 46, 10131024.

Veall, M. and K. Zimmermann (1996). Pseudo-R2 measures for some common limited dependent variable models. Journal of Economic Surveys 10, 241259.

Winkelmann, L. and R. Winkelmann (1998). Why are the unemployed so unhappy? Evidence from panel data. Economica 65, 1-15.

World Bank (2001). World Development Report 2000/2001. Washington, DC: World Bank.

World Bank (2002a). East Timor: Policy Challanges for a New Nation. Washington, DC: World Bank.

World Bank (2002b). Empowerment and Poverty Reduction - A Sourcebook. Washington, DC: World Bank.

World Bank (2003). Timor-Leste - Poverty in a New Nation: Analysis for Action. Washington, DC: World Bank. 
Table 1

Self-rated Welfare and Power in 1999 and 2001

\begin{tabular}{lcccc}
\hline & \multicolumn{2}{c}{ Welfare } & \multicolumn{2}{c}{ Power } \\
& $\mathbf{2 0 0 1}$ & $\mathbf{1 9 9 9}$ & $\mathbf{2 0 0 1}$ & $\mathbf{1 9 9 9}$ \\
\hline \multirow{3}{*}{ Lowest } & 22 & 32 & 5 & 62 \\
& $(2)$ & $(2)$ & $(1)$ & $(2)$ \\
2nd & 38 & 34 & 20 & 22 \\
& $(2)$ & $(1)$ & $(2)$ & $(1)$ \\
3rd & 25 & 19 & 21 & 9 \\
& $(2)$ & $(1)$ & $(1)$ & $(1)$ \\
4th & 11 & 9 & 25 & 4 \\
& $(1)$ & $(1)$ & $(2)$ & $(1)$ \\
5th & 3 & 4 & 15 & 2 \\
& $(1)$ & $(1)$ & $(1)$ & $(1)$ \\
6th & 1 & 1 & 8 & 1 \\
& $(0)$ & $(0)$ & $(1)$ & $(0)$ \\
7th & 0 & 1 & 3 & 0 \\
& $(0)$ & $(0)$ & $(1)$ & $(0)$ \\
8th & 0 & 0 & 1 & 0 \\
& $(0)$ & $(0)$ & $(0)$ & $(0)$ \\
Highest & 0 & 0 & 1 & 0 \\
& $(0)$ & $(0)$ & $(0)$ & $(0)$ \\
& & & & \\
\hline
\end{tabular}

Note: The numbers in brackets refer to standard errors. 
Table 2

Mobility Matrix: Self-rated Welfare from 1999 to 2001

\begin{tabular}{lccccc}
\hline \multirow{2}{*}{1999} & & & & & \\
& Lowest & 2nd & 3rd & 4th & 5th \\
\hline \multirow{2}{*}{ Lowest } & 43 & 39 & 14 & 3 & 1 \\
& $(4)$ & $(3)$ & $(2)$ & $(1)$ & $(0)$ \\
2nd & 16 & 50 & 26 & 7 & 1 \\
& $(2)$ & $(3)$ & $(3)$ & $(1)$ & $(1)$ \\
3rd & 8 & 30 & 40 & 19 & 2 \\
& $(2)$ & $(3)$ & $(4)$ & $(3)$ & $(1)$ \\
4th & 7 & 23 & 29 & 31 & 9 \\
& $(3)$ & $(4)$ & $(4)$ & $(6)$ & $(4)$ \\
5th & 3 & 14 & 20 & 17 & 45 \\
& $(2)$ & $(5)$ & $(5)$ & $(5)$ & $(6)$ \\
& & & & & \\
\hline & Note: The numbers in brackets refer to standard errors.
\end{tabular}

Table 3

Mobility Matrix: Self-rated Power from 1999 to 2001

\begin{tabular}{lccccc}
\hline \multirow{2}{*}{ 1999 } & Lowest & 2nd & $\begin{array}{r}\text { 2001 } \\
\text { 3rd }\end{array}$ & 4th & 5th \\
\hline \multirow{2}{*}{ Lowest } & 5 & 22 & 22 & 26 & 26 \\
& $(1)$ & $(2)$ & $(2)$ & $(2)$ & $(3)$ \\
2nd & 6 & 19 & 21 & 26 & 27 \\
& $(2)$ & $(3)$ & $(2)$ & $(3)$ & $(4)$ \\
3rd & 5 & 17 & 18 & 27 & 33 \\
& $(2)$ & $(4)$ & $(3)$ & $(5)$ & $(6)$ \\
4th & 2 & 14 & 6 & 19 & 59 \\
& $(1)$ & $(5)$ & $(3)$ & $(4)$ & $(10)$ \\
5th & 1 & 9 & 9 & 2 & 78 \\
& $(1)$ & $(5)$ & $(5)$ & $(2)$ & $(13)$ \\
& & & & & \\
\hline & Note: The numbers in brackets refer to standard errors.
\end{tabular}


Table 4

Self-rated Mobility Measures for 1999 to 2001

\begin{tabular}{rcccc}
\hline & $\mathbf{I}$ & $\mathbf{J}$ & $\mathbf{U}$ & $\mathbf{e}$ \\
\hline Welfare & & & & \\
1 & 42.01 & 0.79 & 1.79 & 16 \\
2 & 79.17 & 0.28 & 2.28 & 37 \\
3 & 94.04 & 0.24 & 2.76 & 28 \\
4 & 99.13 & 0.87 & 3.13 & 13 \\
5 & & 1.14 & 3.86 & 4 \\
Total & & 0.51 & 2.76 & 2.5 \\
Power & & & & \\
1 & 27.87 & 2.47 & 3.47 & 2 \\
2 & 60.06 & 1.48 & 3.48 & 12 \\
3 & 81.73 & 0.67 & 3.67 & 11 \\
4 & 94.50 & 0.20 & 4.20 & 10 \\
5 & & 0.53 & 4.47 & 64 \\
Total & & 0.70 & 3.86 & 4.2 \\
& & & & \\
\hline
\end{tabular}


Table 5

Ordered Probit Regressions of Self-rated Welfare and Power in 2001

\begin{tabular}{|c|c|c|c|c|c|c|c|c|c|c|c|c|}
\hline & \multicolumn{6}{|c|}{ WELFARE } & \multicolumn{6}{|c|}{ POWER } \\
\hline & \multicolumn{2}{|c|}{ MODEL 1} & \multicolumn{2}{|c|}{ MODEL 2} & \multicolumn{2}{|c|}{ MODEL 3} & \multicolumn{2}{|c|}{ MODEL 1} & \multicolumn{2}{|c|}{ MODEL 2} & \multicolumn{2}{|c|}{ MODEL 3} \\
\hline & Coef & )$^{\text {z-sts }}$ & Coef & Z-sts & Coef & z-sts & Coef & z-sts & Coef & z-sts & Coef & z-sts \\
\hline \multicolumn{13}{|l|}{ Economic } \\
\hline Welfare ratio & & & & & 0.013 & 3.1 & & & & & 0.007 & 1.7 \\
\hline Village welfare ratio & & & & & -0.021 & -1.4 & & & & & 0.007 & 0.5 \\
\hline Housing conditions & & & 0.094 & 3.0 & 0.114 & 4.1 & & & 0.034 & 1.1 & 0.039 & 1.5 \\
\hline Per capita $\mathrm{HH}$ assets & & & 0.000 & 9.9 & 0.000 & 10.2 & & & 0.000 & 5.1 & 0.000 & 5.1 \\
\hline Per capita aid assistance & & & 0.000 & 2.6 & 0.000 & 3.8 & & & 0.000 & 1.9 & 0.000 & 2.0 \\
\hline Paved Road & & & 0.082 & 5.3 & 0.078 & 5.5 & & & 0.020 & 1.4 & 0.015 & 1.1 \\
\hline Unemployed & & & -0.342 & -4.1 & -0.307 & -3.7 & & & 0.080 & 1.0 & 0.106 & 1.3 \\
\hline Farmer & & & -0.215 & -3.3 & -0.172 & -2.7 & & & -0.122 & -1.9 & -0.084 & -1.4 \\
\hline Pensioner & & & -0.153 & -2.1 & -0.149 & -2.1 & & & -0.065 & -0.9 & -0.042 & -0.6 \\
\hline Coffee farmer & & & -0.104 & -1.4 & -0.108 & -1.4 & & & -0.061 & -0.8 & -0.064 & -0.9 \\
\hline Student & & & -0.063 & -0.8 & -0.015 & -0.2 & & & -0.003 & 0.0 & 0.066 & 0.9 \\
\hline \multicolumn{13}{|l|}{ Social } \\
\hline Mother Tetun & -0.103 & -1.6 & -0.100 & -1.5 & -0.098 & -1.6 & 0.204 & 3.2 & 0.197 & 3.1 & 0.245 & 4.1 \\
\hline Speaks Tetun & 0.203 & 3.6 & 0.214 & 3.8 & 0.295 & 5.5 & 0.022 & 0.4 & 0.030 & 0.6 & 0.120 & 2.4 \\
\hline Speaks Portuguese & 0.268 & 4.7 & 0.199 & 3.4 & 0.173 & 3.0 & 0.158 & 2.8 & 0.133 & 2.3 & 0.105 & 1.9 \\
\hline Mother Bunak & 0.198 & 3.3 & 0.110 & 1.8 & 0.235 & 4.5 & 0.216 & 3.8 & 0.169 & 2.9 & 0.078 & 1.5 \\
\hline Mother Macasae & -0.041 & -0.7 & -0.097 & -1.7 & -0.102 & -2.1 & 0.046 & 0.8 & 0.018 & 0.3 & 0.144 & 3.0 \\
\hline Mother Mambae & 0.021 & 0.4 & 0.067 & 1.3 & 0.126 & 2.9 & -0.026 & -0.5 & -0.026 & -0.5 & 0.143 & 3.4 \\
\hline Mother tongue of sub-district & 0.082 & 2.2 & 0.085 & 2.2 & 0.039 & 1.1 & 0.087 & 2.4 & 0.089 & 2.4 & 0.028 & 0.8 \\
\hline Radio or TV (\#) & 0.060 & 2.1 & 0.004 & 0.2 & -0.013 & -0.5 & 0.103 & 3.8 & 0.077 & 2.8 & 0.054 & 2.0 \\
\hline $\mathrm{HH}$ attends community group & -0.188 & -1.5 & -0.217 & -1.7 & -0.153 & -1.2 & 0.062 & 0.5 & 0.047 & 0.4 & 0.196 & 1.6 \\
\hline Village leader years of education & 0.003 & 0.4 & 0.001 & 0.1 & & & 0.029 & 4.0 & 0.028 & 3.8 & & \\
\hline Village leader years living in village & -0.001 & -0.5 & -0.001 & -0.8 & & & 0.008 & 5.1 & 0.008 & 5.0 & & \\
\hline \multicolumn{13}{|l|}{ Basic } \\
\hline Household size & 0.038 & 5.2 & 0.039 & 5.1 & 0.035 & 4.7 & 0.023 & 3.3 & 0.020 & 2.8 & 0.021 & 2.9 \\
\hline Share 0-6 year-old & -0.205 & -1.9 & -0.133 & -1.2 & -0.085 & -0.8 & -0.231 & -2.2 & -0.196 & -1.9 & -0.120 & -1.2 \\
\hline Share 7-14 year-old & -0.078 & -0.7 & -0.070 & -0.6 & -0.014 & -0.1 & 0.006 & 0.1 & 0.036 & 0.3 & 0.064 & 0.6 \\
\hline Share 50 years or older & 0.026 & 0.3 & 0.017 & 0.2 & -0.004 & 0.0 & -0.070 & -0.8 & -0.054 & -0.6 & -0.010 & -0.1 \\
\hline Male & -0.050 & -1.6 & -0.034 & -0.8 & -0.050 & -1.2 & 0.008 & 0.3 & 0.036 & 0.9 & 0.032 & 0.8 \\
\hline Age & 0.007 & 1.1 & 0.004 & 0.6 & 0.005 & 0.7 & 0.003 & 0.6 & 0.006 & 1.1 & 0.008 & 1.4 \\
\hline Age square & 0.000 & -0.6 & 0.000 & -0.1 & 0.000 & -0.1 & 0.000 & 0.0 & 0.000 & -0.7 & 0.000 & -0.9 \\
\hline Married & 0.221 & 3.8 & 0.185 & 3.0 & 0.213 & 3.4 & 0.160 & 2.9 & 0.169 & 2.8 & 0.191 & 3.2 \\
\hline Single & 0.185 & 2.4 & 0.133 & 1.7 & 0.162 & 2.1 & 0.169 & 2.3 & 0.145 & 1.9 & 0.170 & 2.3 \\
\hline Education & 0.085 & 6.4 & 0.059 & 4.2 & 0.051 & 3.7 & 0.092 & 7.1 & 0.078 & 5.7 & 0.070 & 5.2 \\
\hline Parental schooling & 0.202 & 3.2 & 0.152 & 2.4 & 0.114 & 1.8 & 0.162 & 2.6 & 0.143 & 2.3 & 0.096 & 1.6 \\
\hline Community & & & & & & & & & & & & \\
\hline Hamlet infrastructure & 0.017 & 1.4 & -0.014 & -1.1 & & & -0.021 & -1.8 & -0.031 & -2.5 & & \\
\hline Hamlet piped water & 0.107 & 2.4 & 0.104 & 2.3 & & & 0.024 & 0.6 & 0.017 & 0.4 & & \\
\hline Village teacher-student ratio & -3.4 & -1.5 & -4.4 & -1.9 & & & 6.8 & 3.1 & 6.8 & 3.0 & & \\
\hline Village classroom-student ratio & 0.7 & 0.3 & 5.7 & 2.0 & & & -9.5 & -3.6 & -7.9 & -2.9 & & \\
\hline Village health service days pc & -12.5 & -1.5 & -16.0 & -1.9 & & & -24.3 & -3.1 & -23.7 & -3.0 & & \\
\hline Village income sources (\#) & -0.242 & -8.4 & -0.245 & -8.5 & & & -0.227 & -8.2 & -0.228 & -8.2 & & \\
\hline Village coffee & -0.259 & -4.9 & -0.222 & -3.9 & & & -0.254 & -4.9 & -0.246 & -4.4 & & \\
\hline Village other & -0.056 & -0.9 & -0.058 & -0.9 & & & 0.007 & 0.1 & 0.010 & 0.2 & & \\
\hline Sub-district capital & -0.044 & -0.9 & 0.014 & 0.3 & & & -0.196 & -3.9 & -0.182 & -3.6 & & \\
\hline District capital & -0.132 & -1.2 & -0.179 & -1.6 & & & 0.258 & 2.4 & 0.249 & 2.3 & & \\
\hline Other Urban & 0.223 & 2.8 & 0.192 & 2.4 & & & -0.024 & -0.3 & -0.036 & -0.5 & & \\
\hline Rural West & -0.023 & -0.3 & 0.010 & 0.1 & & & -0.323 & -4.3 & -0.303 & -3.7 & & \\
\hline Rural Center & 0.105 & 1.4 & 0.045 & 0.6 & & & 0.179 & 2.5 & 0.163 & 2.1 & & \\
\hline$\underline{\text { Rural East }}$ & -0.31 & -4.0 & -0.23 & -2.8 & & & -0.111 & -1.5 & -0.063 & -0.8 & & \\
\hline Aldrich-Nelson Pseudo R2 & 0.124 & & 0.162 & & 0.138 & & 0.127 & & 0.137 & & 0.087 & \\
\hline Cutoffs & -0.53 & 0.21 & -0.56 & 0.23 & 0.23 & 0.18 & -1.29 & 0.20 & -1.26 & 0.22 & -0.81 & 0.18 \\
\hline & 0.57 & 0.21 & 0.56 & 0.23 & 1.34 & 0.18 & -0.25 & 0.20 & -0.21 & 0.22 & 0.20 & 0.17 \\
\hline & 1.41 & 0.21 & 1.43 & 0.23 & 2.19 & 0.18 & 0.35 & 0.20 & 0.40 & 0.22 & 0.79 & 0.17 \\
\hline & 2.22 & 0.21 & 2.25 & 0.23 & 3.00 & 0.19 & 1.05 & 0.20 & 1.10 & 0.22 & 1.47 & 0.18 \\
\hline & 2.80 & 0.22 & 2.85 & 0.23 & 3.61 & 0.19 & 1.60 & 0.20 & 1.65 & 0.22 & 2.02 & 0.18 \\
\hline & & & & & & & 2.11 & 0.20 & 2.16 & 0.22 & 2.53 & 0.18 \\
\hline & & & & & & & 2.52 & 0.21 & 2.57 & 0.22 & 2.92 & 0.18 \\
\hline & & & & & & & 2.82 & 0.21 & 2.87 & 0.22 & 3.22 & 0.18 \\
\hline
\end{tabular}


Table 6

Predicted Probabilities of Self-rated Welfare and Power in 2001: Wage Earner and Mother Tongue Tetun

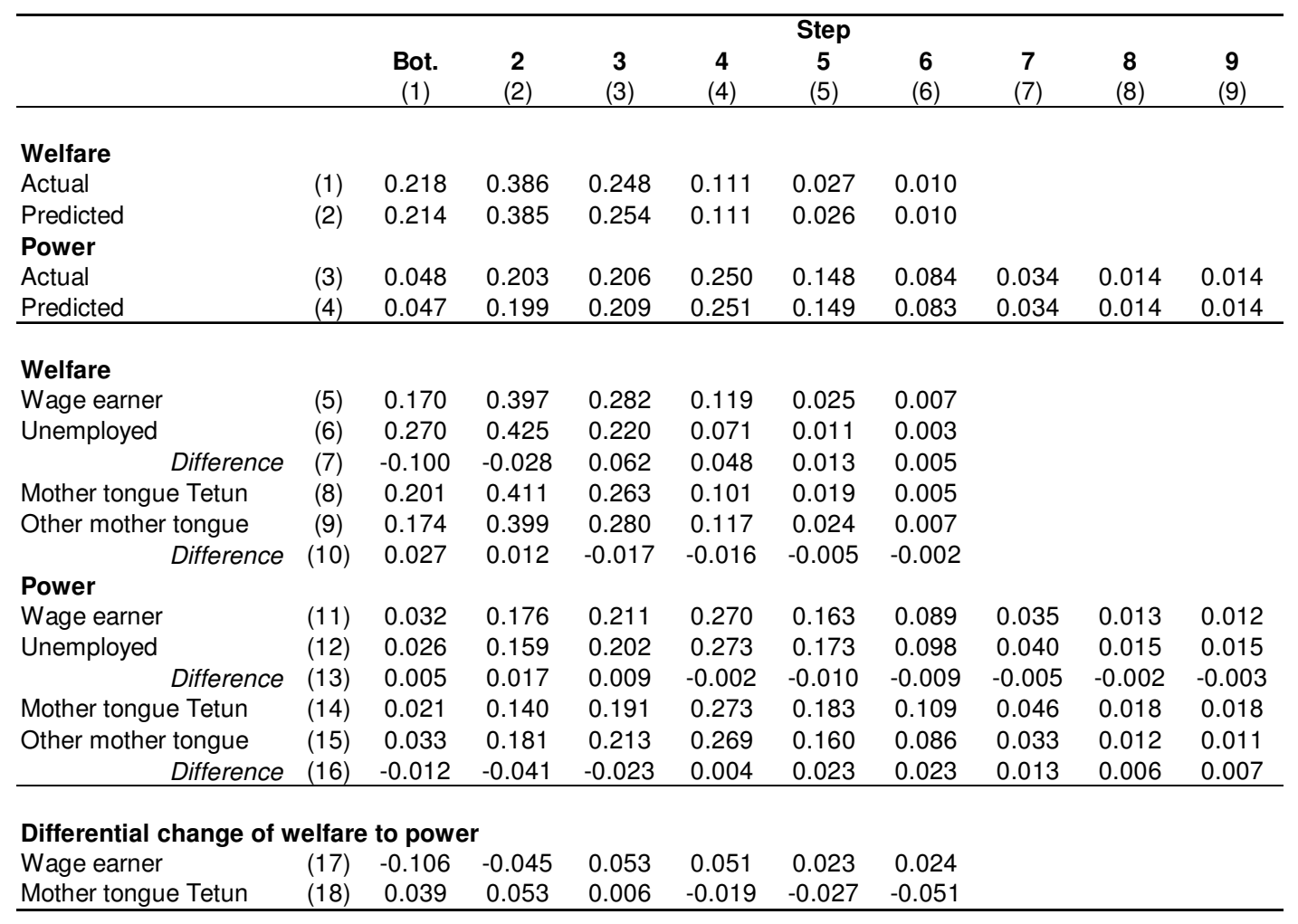


Table 7

Marginal Effects of Ordered Probit Regressions and OLS Regressions of Self-rated Welfare and Power in 2001

\begin{tabular}{|c|c|c|c|c|c|c|c|c|c|c|c|c|c|c|}
\hline & \multirow{3}{*}{$\begin{array}{c}\text { Change } \\
\text { (1) }\end{array}$} & \multicolumn{6}{|c|}{ WELFARE MODEL 2} & \multicolumn{6}{|c|}{ POWER MODEL 2} & \multirow{3}{*}{$\begin{array}{c}\text { F-Test } \\
\text { OLS } \\
(\mathrm{Pr}>\mathrm{F}) \\
(14) \\
\end{array}$} \\
\hline & & \multicolumn{4}{|c|}{ Step } & \multicolumn{2}{|c|}{ OLS } & \multicolumn{4}{|c|}{ Step } & \multicolumn{2}{|c|}{ OLS } & \\
\hline & & $\begin{array}{l}\text { Bot. } \\
\text { (2) }\end{array}$ & $\begin{array}{c}2 \\
(3)\end{array}$ & $\begin{array}{c}3 \\
(4)\end{array}$ & $\begin{array}{c}\mathbf{4} \\
(5)\end{array}$ & $\begin{array}{c}\text { Coeff. } \\
(6)\end{array}$ & $\begin{array}{c}\text { t-stat } \\
\text { (7) }\end{array}$ & $\begin{array}{c}\text { Bot. } \\
\text { (8) }\end{array}$ & $\begin{array}{c}2 \\
(9)\end{array}$ & $\begin{array}{c}\mathbf{3} \\
(10)\end{array}$ & $\begin{array}{c}\mathbf{4} \\
(11)\end{array}$ & $\begin{array}{c}\text { Coeff. } \\
\text { (12) }\end{array}$ & $\begin{array}{c}\text { t-stat } \\
(13)\end{array}$ & \\
\hline \multicolumn{15}{|l|}{ Economic } \\
\hline Housing conditions & MargEfct & -0.024 & -0.012 & 0.015 & 0.015 & 0.087 & 2.9 & -0.002 & -0.007 & -0.004 & 0.001 & 0.038 & 0.8 & 0.382 \\
\hline Per capita HH assets & MargEfct & $-8 . E-08$ & $-4 . E-08$ & 5.E-08 & 5.E-08 & 3.E-07 & 10.5 & $-1 . E-08$ & $-3 . E-08$ & $-2 . E-08$ & 5.E-09 & 2.E- -07 & 4.8 & 0.094 \\
\hline Per capita aid assistance & MargEfct & $-2 . E-08$ & $-1 . E-08$ & 1.E-08 & 1.E-08 & 6.E-08 & 2.3 & $-4 . E-09$ & $-1 . \mathrm{E}-08$ & $-6 . E-09$ & 2.E-09 & 7.E-08 & 1.6 & 0.938 \\
\hline Paved Road & $0 \rightarrow 1$ & -0.027 & -0.003 & 0.016 & 0.010 & 0.081 & 5.5 & -0.002 & -0.004 & -0.002 & 0.001 & 0.022 & 1.0 & 0.031 \\
\hline Unemployed & $0 \rightarrow 1$ & 0.100 & 0.028 & -0.062 & -0.048 & -0.341 & -4.3 & -0.005 & -0.017 & -0.009 & 0.002 & 0.100 & 0.8 & 0.002 \\
\hline Farmer & $0 \rightarrow 1$ & 0.059 & 0.024 & -0.037 & -0.033 & -0.219 & -3.5 & 0.009 & 0.026 & 0.012 & -0.005 & -0.185 & -1.9 & 0.768 \\
\hline Pensioner & $0 \rightarrow 1$ & 0.041 & 0.018 & -0.026 & -0.024 & -0.185 & -2.7 & 0.005 & 0.014 & 0.007 & -0.003 & -0.113 & -1.1 & 0.566 \\
\hline Coffee farmer & $0 \rightarrow 1$ & 0.028 & 0.012 & -0.018 & -0.016 & -0.123 & -1.7 & 0.004 & 0.013 & 0.006 & -0.003 & -0.084 & -0.7 & 0.778 \\
\hline Student & $0 \rightarrow 1$ & 0.017 & 0.008 & -0.011 & -0.010 & -0.078 & -1.1 & 0.000 & 0.001 & 0.000 & 0.000 & 0.016 & 0.2 & 0.486 \\
\hline $\begin{array}{l}\text { Social } \\
\text { Mother Tetun }\end{array}$ & \multicolumn{13}{|c|}{ Social } & 0.001 \\
\hline Speaks Tetun & $0 \rightarrow 1$ & $\begin{array}{l}-0.060 \\
-0.70\end{array}$ & $\begin{array}{l}-0.022 \\
-0.02\end{array}$ & 0.038 & 0.032 & 0.169 & 3.2 & $\begin{array}{l}-0.002 \\
-0.002-12\end{array}$ & -0.006 & $\begin{array}{l}-0.020 \\
-0.003\end{array}$ & 0.001 & 0.015 & $\begin{array}{l}.1 \\
0.2\end{array}$ & 0.113 \\
\hline Speaks Portuguese & $0 \rightarrow 1$ & -0.048 & -0.030 & 0.030 & 0.033 & 0.197 & 3.5 & $\begin{array}{l}-0.008 \\
-0.02-1\end{array}$ & -0.028 & -0.015 & 0.003 & 0.232 & 2.7 & 0.736 \\
\hline Mother Bunak & $0 \rightarrow 1$ & -0.027 & -0.016 & 0.017 & 0.018 & 0.121 & 2.1 & -0.010 & -0.035 & -0.019 & 0.003 & 0.245 & 2.8 & 0.241 \\
\hline Mother Macasae & $0 \rightarrow 1$ & 0.026 & 0.012 & -0.017 & -0.015 & -0.099 & -1.8 & -0.001 & -0.004 & -0.002 & 0.001 & 0.039 & 0.5 & 0.179 \\
\hline Mother Mambae & $0 \rightarrow 1$ & -0.017 & -0.009 & 0.011 & 0.011 & 0.067 & 1.3 & 0.002 & 0.006 & 0.003 & -0.001 & -0.018 & -0.2 & 0.358 \\
\hline Mother tongue of sub-district & $0 \rightarrow 1$ & -0.022 & -0.011 & 0.014 & 0.013 & 0.083 & 2.3 & -0.006 & -0.019 & -0.009 & 0.003 & 0.162 & 2.9 & 0.243 \\
\hline Radio or TV (\#) & $0->1$ & -0.001 & -0.001 & 0.001 & 0.001 & 0.015 & 0.6 & -0.006 & -0.017 & -0.008 & 0.004 & 0.120 & 2.9 & 0.036 \\
\hline $\mathrm{HH}$ attends community group & MargEfct & 0.057 & 0.028 & -0.036 & -0.035 & -0.217 & -1.8 & -0.003 & -0.010 & -0.005 & 0.002 & 0.256 & 1.3 & 0.037 \\
\hline Village leader years of education & MargEfct & $-3 . E-04$ & $-1 . \mathrm{E}-04$ & 2.E-04 & 2.E-04 & 0.001 & 0.1 & $-2 . \mathrm{E}-03$ & $-6 . \mathrm{E}-03$ & $-3 . E-03$ & 1.E-03 & 0.049 & 4.3 & 0.000 \\
\hline \multirow{2}{*}{\multicolumn{15}{|c|}{$\begin{array}{l}\text { Basic } \\
\text { Bander years living in village } \\
\end{array}$}} \\
\hline & & & & & & & & & & & & & & \\
\hline Household size & MargEfct & -0.010 & -0.005 & 0.006 & 0.006 & 0.039 & 5.4 & -0.001 & -0.004 & -0.002 & 0.001 & 0.032 & 2.9 & 0.618 \\
\hline Share $0-6$ year-old & MargEfct & 0.035 & 0.017 & -0.022 & -0.021 & -0.087 & -0.9 & 0.014 & 0.042 & 0.021 & -0.007 & -0.343 & -2.2 & 0.176 \\
\hline Share 7-14 year-old & MargEfct & 0.018 & 0.009 & -0.011 & -0.011 & -0.069 & -0.7 & -0.003 & -0.008 & -0.004 & 0.001 & -0.015 & -0.1 & 0.778 \\
\hline Share 50 years or older & MargEfct & -0.005 & -0.002 & 0.003 & 0.003 & 0.046 & 0.5 & 0.004 & 0.012 & 0.006 & -0.002 & -0.115 & -0.8 & 0.345 \\
\hline Male & $0 \rightarrow 1$ & 0.009 & 0.004 & -0.006 & -0.005 & -0.047 & -1.2 & -0.003 & -0.008 & -0.004 & 0.001 & 0.046 & 0.7 & 0.214 \\
\hline Age & MargEfct & -0.001 & 0.000 & 0.001 & 0.001 & 0.003 & 0.5 & 0.000 & -0.001 & -0.001 & 0.000 & 0.011 & 1.2 & 0.488 \\
\hline Age square & MargEfct & 1.E-06 & 7.E-07 & $-9 . E-07$ & $-9 . E-07$ & 2.E-06 & 0.0 & 3.E-06 & 1.E-05 & 5.E-06 & $-2 . E-06$ & $-8 . E-05$ & -0.8 & 0.487 \\
\hline Married & $0 \rightarrow 1$ & -0.049 & -0.023 & 0.031 & 0.029 & 0.163 & 2.8 & -0.012 & -0.036 & -0.018 & 0.006 & 0.234 & 2.6 & 0.513 \\
\hline Single & $0 \rightarrow 1$ & -0.034 & -0.018 & 0.021 & 0.021 & 0.104 & 1.4 & -0.010 & -0.031 & -0.016 & 0.004 & 0.196 & 1.7 & 0.503 \\
\hline Education & $0 \rightarrow 1$ & -0.017 & -0.006 & 0.011 & 0.009 & 0.060 & 4.5 & -0.007 & -0.018 & -0.007 & 0.005 & 0.118 & 5.7 & 0.019 \\
\hline Parental schooling & $0 \rightarrow 1$ & -0.037 & -0.023 & 0.023 & 0.025 & 0.147 & 2.4 & -0.009 & -0.030 & -0.016 & 0.003 & 0.233 & 2.5 & 0.447 \\
\hline \multicolumn{15}{|l|}{ Community } \\
\hline Hamlet infrastructure & MargEfct & 0.004 & 0.002 & -0.002 & -0.002 & -0.007 & -0.6 & 0.002 & 0.007 & 0.003 & -0.001 & -0.038 & -2.0 & 0.171 \\
\hline Hamlet piped water & $0 \rightarrow 1$ & $\begin{array}{l}-0.026 \\
-0.02\end{array}$ & $\begin{array}{l}-0.014 \\
-0.02\end{array}$ & 0.017 & 0.017 & 0.094 & 2.1 & $\begin{array}{l}-0.001 \\
-0.00\end{array}$ & $\begin{array}{l}-0.004 \\
-0.00\end{array}$ & $\begin{array}{l}-0.002 \\
-0.002\end{array}$ & 0.001 & 0.020 & 0.3 & 0.364 \\
\hline Village teacher-student ratio & MargEfct & 1.146 & 0.574 & -0.723 & -0.700 & -4.739 & -2.1 & -0.476 & -1.460 & -0.720 & 0.238 & 10.688 & 3.1 & 0.000 \\
\hline udent ratio & MargEfct & -1.473 & -0.738 & 0.930 & 0.900 & 5.981 & 2.2 & 0.549 & 1.686 & 0.832 & -0.275 & -13.710 & -3.3 & 0.000 \\
\hline Village health service days $p c$ & MargEfct & 4.180 & 2.093 & -2.639 & -2.554 & -17.006 & -2.2 & 1.655 & 5.078 & 2.506 & -0.828 & -38.458 & -3.2 & 0.139 \\
\hline Village income sources (\#) & $0 \rightarrow 1$ & 0.032 & 0.059 & -0.005 & -0.045 & -0.236 & -8.6 & 0.005 & 0.031 & 0.033 & 0.022 & -0.319 & -7.5 & 0.100 \\
\hline Village coffee & $0 \rightarrow 1$ & 0.062 & 0.023 & -0.039 & -0.033 & -0.215 & -3.9 & 0.020 & 0.054 & 0.022 & -0.014 & -0.392 & -4.6 & 0.079 \\
\hline Village other & $0 \rightarrow 1$ & 0.015 & 0.007 & -0.010 & -0.009 & -0.046 & -0.8 & -0.001 & -0.002 & -0.001 & 0.000 & -0.004 & 0.0 & 0.709 \\
\hline Sub-district capital & $0 \rightarrow 1$ & -0.004 & -0.002 & 0.002 & 0.002 & 0.015 & 0.3 & 0.014 & 0.040 & 0.017 & -0.009 & -0.266 & -3.4 & 0.002 \\
\hline District capital & $0 \rightarrow 1$ & 0.050 & 0.018 & -0.031 & -0.027 & -0.169 & -1.6 & -0.014 & -0.050 & -0.030 & 0.001 & 0.414 & 2.5 & 0.003 \\
\hline Other Urban & $0 \rightarrow 1$ & -0.047 & -0.029 & 0.029 & 0.032 & 0.179 & 2.3 & 0.003 & 0.008 & 0.004 & -0.001 & -0.159 & -1.3 & 0.018 \\
\hline Rural West & $0 \rightarrow 1$ & -0.003 & -0.001 & 0.002 & 0.002 & -0.025 & -0.3 & 0.026 & 0.068 & 0.026 & -0.019 & -0.543 & -4.4 & 0.000 \\
\hline Rural Center & $0 \rightarrow 1$ & -0.011 & -0.006 & 0.007 & 0.007 & 0.023 & 0.3 & -0.011 & -0.034 & -0.018 & 0.004 & 0.184 & 1.6 & 0.254 \\
\hline Rural East & $0 \rightarrow 1$ & 0.064 & 0.024 & -0.040 & -0.035 & -0.217 & -2.8 & 0.005 & 0.014 & 0.006 & -0.003 & -0.172 & -1.4 & 0.755 \\
\hline Constant & & & & & & 2.140 & 10.0 & & & & & 3.019 & 9.1 & \\
\hline
\end{tabular}


Table 8

Ordered Probit Regressions of Changes in Self-rated Welfare and Power from 1999 to 2001

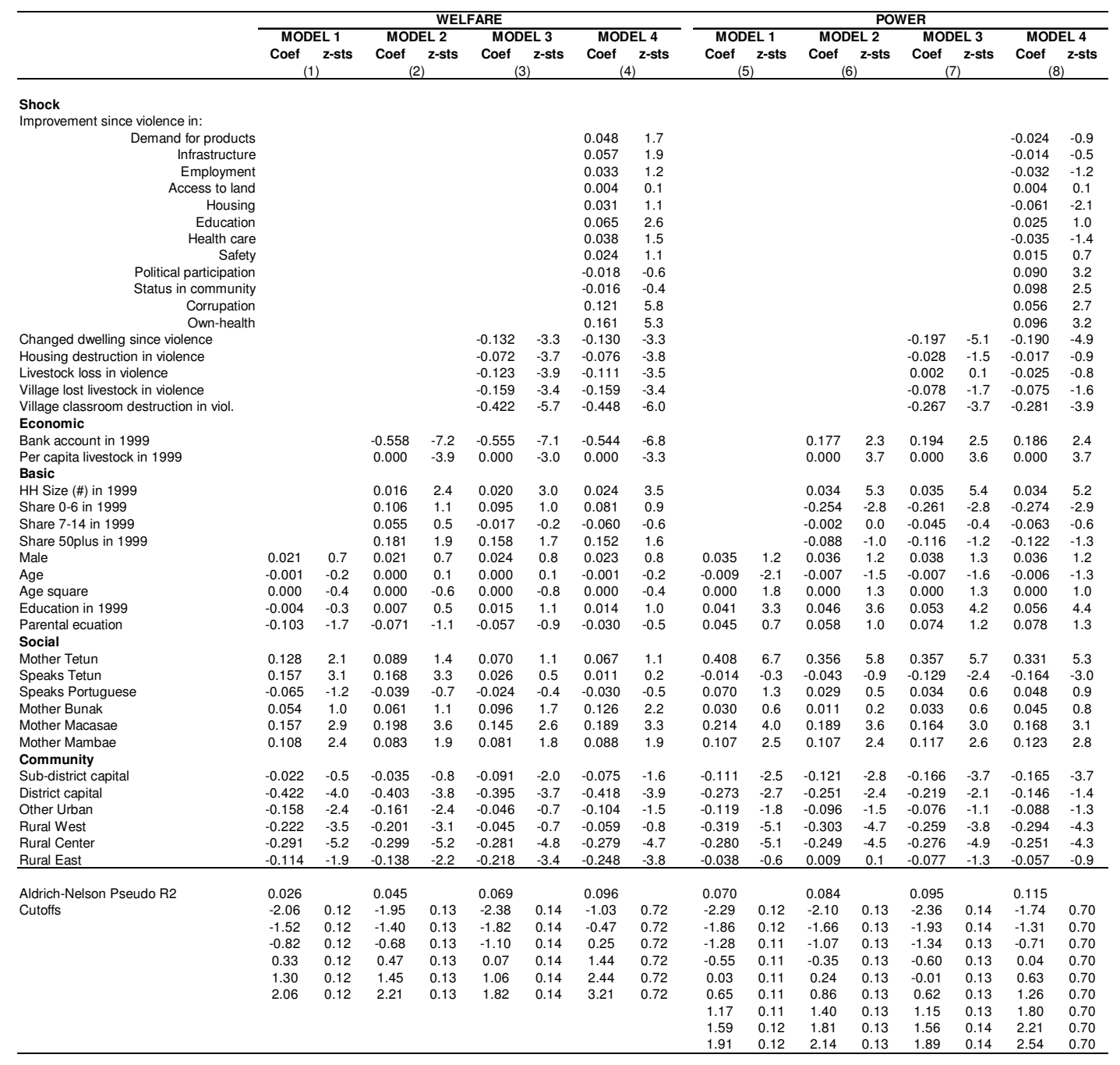


Table 9

Predicted Probabilities of Changes in Self-rated Welfare and Power from 1999 to 2001: Bank Account in 1999, Mother Tongue Tetun and Livestock Loss in Violence

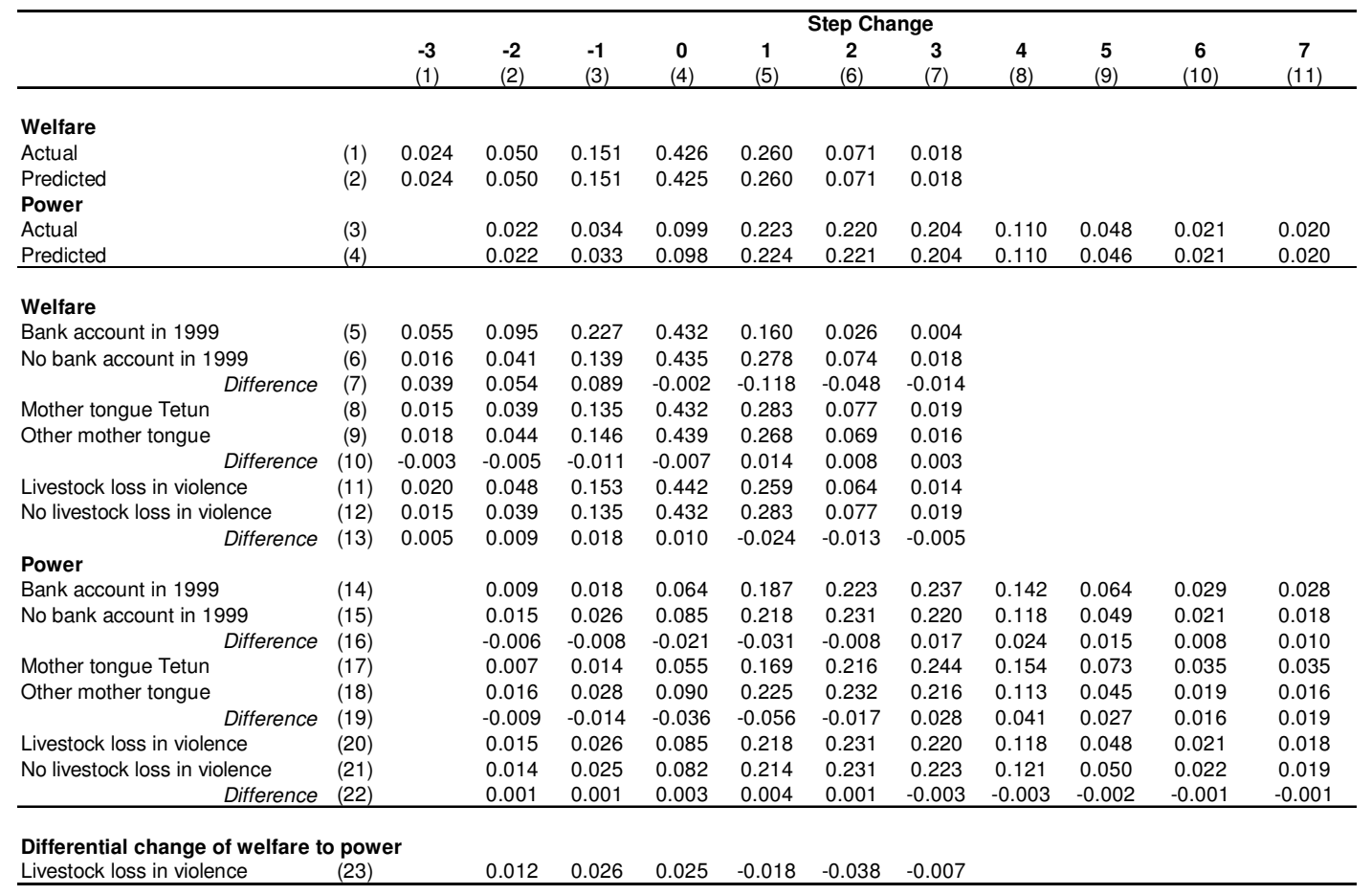


Table 10

OLS Regressions of Changes in Self-rated Welfare and Power from 1999 to 2001

\begin{tabular}{|c|c|c|c|c|c|c|c|c|c|c|c|c|c|c|}
\hline & \multirow{3}{*}{$\begin{array}{l}\text { Change } \\
\text { (1) }\end{array}$} & \multicolumn{6}{|c|}{ WELFARE MODEL 4} & \multicolumn{6}{|c|}{ POWER MODEL 4} & \multirow{3}{*}{$\begin{array}{c}\text { F-Test } \\
\text { OLS } \\
(\mathrm{Pr}>\mathrm{F}) \\
(14)\end{array}$} \\
\hline & & \multicolumn{4}{|c|}{ Step change } & \multicolumn{2}{|c|}{ OLS } & \multicolumn{4}{|c|}{ Step change } & \multicolumn{2}{|c|}{ OLS } & \\
\hline & & $\begin{array}{l}-2 \\
(2)\end{array}$ & $\begin{array}{l}-1 \\
(3)\end{array}$ & $\begin{array}{c}0 \\
(4) \\
\end{array}$ & $\begin{array}{l}1 \\
(5)\end{array}$ & $\begin{array}{c}\text { Coeff. } \\
\text { (6) }\end{array}$ & $\begin{array}{c}\text { t-stat } \\
(7)\end{array}$ & $\begin{array}{l}-2 \\
(8)\end{array}$ & $\begin{array}{l}-1 \\
(9)\end{array}$ & $\begin{array}{c}0 \\
(10)\end{array}$ & $\begin{array}{c}1 \\
(11)\end{array}$ & $\begin{array}{l}\text { Coeff. } \\
(12)\end{array}$ & $\begin{array}{c}\text { t-stat } \\
(13)\end{array}$ & \\
\hline \multirow{2}{*}{\multicolumn{15}{|c|}{$\begin{array}{l}\text { Shock } \\
\text { Improvement since violence in: }\end{array}$}} \\
\hline & & & & & & & & & & & & & & 0.067 \\
\hline Infrastructure & $3->4$ & -0.004 & -0.009 & -0.005 & 0.012 & 0.056 & 1.8 & 0.001 & 0.001 & 0.002 & 0.002 & -0.035 & -0.7 & 0.125 \\
\hline Employment & $3->4$ & -0.003 & -0.005 & -0.003 & 0.007 & 0.032 & 1.2 & 0.001 & 0.002 & 0.004 & 0.005 & -0.058 & -1.3 & 0.080 \\
\hline Access to land & 3->4 & 0.000 & -0.001 & 0.000 & 0.001 & 0.001 & 0.0 & 0.000 & 0.000 & -0.001 & -0.001 & 0.001 & 0.0 & 0.996 \\
\hline Housing & 3->4 & -0.002 & -0.005 & -0.003 & 0.007 & 0.034 & 1.1 & 0.002 & 0.003 & 0.007 & 0.010 & -0.109 & -2.3 & 0.011 \\
\hline Education & 3->4 & -0.005 & -0.011 & -0.005 & 0.014 & 0.065 & 2.5 & -0.001 & -0.001 & -0.003 & -0.004 & 0.033 & 0.8 & 0.504 \\
\hline Health care & $3->4$ & -0.003 & -0.006 & -0.003 & 0.008 & 0.039 & 1.4 & 0.001 & 0.002 & 0.004 & 0.006 & -0.066 & -1.6 & 0.038 \\
\hline Safety & 3->4 & -0.002 & -0.004 & -0.002 & 0.005 & 0.028 & 1.2 & -0.001 & -0.001 & -0.002 & -0.002 & 0.020 & 0.6 & 0.859 \\
\hline Political participation & 3->4 & 0.001 & 0.003 & 0.002 & -0.004 & -0.020 & -0.7 & -0.003 & -0.005 & -0.011 & -0.014 & 0.132 & 2.8 & 0.006 \\
\hline Status in community & $3->4$ & 0.001 & 0.003 & 0.001 & -0.003 & -0.022 & -0.5 & -0.004 & -0.005 & -0.012 & -0.016 & 0.148 & 2.3 & 0.027 \\
\hline Corrupation & $1 \rightarrow 2$ & -0.003 & -0.007 & -0.009 & -0.001 & 0.133 & 6.1 & -0.002 & -0.003 & -0.007 & -0.009 & 0.088 & 2.6 & 0.257 \\
\hline Own-health & $1->2$ & -0.006 & -0.012 & -0.014 & 0.000 & 0.163 & 5.2 & -0.004 & -0.006 & -0.012 & -0.014 & 0.162 & 3.3 & 0.994 \\
\hline Changed dwelling since violence & $0 \rightarrow 1$ & 0.010 & 0.023 & 0.030 & 0.003 & -0.135 & -3.3 & 0.008 & 0.010 & 0.023 & 0.030 & -0.292 & -4.5 & 0.040 \\
\hline Housing destruction in violence & $0->1$ & 0.001 & 0.002 & 0.003 & 0.001 & -0.074 & -3.6 & 0.001 & 0.001 & 0.002 & 0.003 & -0.023 & -0.7 & 0.176 \\
\hline Livestock loss in violence & $0 \rightarrow 1$ & 0.009 & 0.018 & 0.010 & -0.024 & -0.114 & -3.4 & 0.001 & 0.001 & 0.003 & 0.004 & -0.038 & -0.7 & 0.221 \\
\hline Village lost livestock in violence & $0->1$ & 0.011 & 0.026 & 0.017 & -0.033 & -0.157 & -3.2 & 0.003 & 0.004 & 0.009 & 0.012 & -0.147 & -1.9 & 0.909 \\
\hline $\begin{array}{l}\text { Village classroom destruction in viol. } \\
\text { Economic }\end{array}$ & MargEfct & 0.035 & 0.073 & 0.040 & -0.097 & -0.458 & -5.9 & 0.010 & 0.014 & 0.033 & 0.046 & -0.389 & -3.2 & 0.632 \\
\hline Bank account in 1999 & $0->1$ & 0.054 & 0.088 & -0.002 & -0.118 & -0.600 & -7.3 & -0.006 & -0.008 & -0.021 & -0.031 & 0.336 & 2.6 & 0.000 \\
\hline Per capita livestock in 1999 & MargEfct & 7.E-07 & 1.E-06 & 8.E-07 & $-2 . E-06$ & $-1 . E-05$ & -3.8 & $-3 . E-07$ & $-5 . E-07$ & $-1 . E-06$ & $-2 . E-06$ & $2 \mathrm{E}-05$ & 3.7 & 0.000 \\
\hline \multicolumn{15}{|l|}{ Basic } \\
\hline HH Size (\#) in 1999 & MargEfct & -0.002 & -0.004 & -0.002 & 0.005 & 0.022 & 3.1 & -0.001 & -0.002 & -0.004 & -0.006 & 0.057 & 5.2 & 0.007 \\
\hline Share 0-6 in 1999 & MargEfct & -0.006 & -0.013 & -0.007 & 0.018 & 0.085 & 0.9 & 0.010 & 0.013 & 0.033 & 0.045 & -0.479 & -3.1 & 0.002 \\
\hline Share 7-14 in 1999 & MargEfct & 0.005 & 0.010 & 0.005 & -0.013 & -0.051 & -0.5 & 0.002 & 0.003 & 0.008 & 0.010 & -0.130 & -0.8 & 0.697 \\
\hline Share 50plus in 1999 & MargEfct & -0.012 & -0.025 & -0.014 & 0.033 & 0.165 & 1.7 & 0.004 & 0.006 & 0.014 & 0.020 & -0.222 & -1.4 & 0.036 \\
\hline Male & $0->1$ & -0.002 & -0.004 & -0.002 & 0.005 & 0.027 & 0.9 & -0.001 & -0.002 & -0.004 & -0.006 & 0.062 & 1.3 & 0.544 \\
\hline Age & MargEfct & 0.000 & 0.000 & 0.000 & 0.000 & -0.001 & -0.2 & 0.000 & 0.000 & 0.001 & 0.001 & -0.009 & -1.1 & 0.414 \\
\hline Age square & MargEfct & 2.E-06 & 3.E-06 & 2.E-06 & $-4 . E-06$ & $-2 . E-05$ & -0.4 & -0.002 & -0.003 & -0.007 & -0.009 & 0.000 & 0.9 & 0.341 \\
\hline Education in 1999 & $0->1$ & -0.003 & -0.007 & -0.009 & 0.000 & 0.010 & 0.8 & -0.002 & -0.003 & -0.007 & -0.009 & 0.092 & 4.4 & 0.001 \\
\hline Parental ecuation & $0->1$ & 0.002 & 0.005 & 0.003 & -0.007 & -0.033 & -0.5 & -0.003 & -0.004 & -0.009 & -0.013 & 0.129 & 1.3 & 0.182 \\
\hline \multicolumn{15}{|l|}{ Social } \\
\hline Mother Tetun & $0>1$ & -0.005 & -0.011 & -0.007 & 0.014 & 0.058 & 0.9 & -0.009 & -0.014 & -0.036 & -0.056 & 0.545 & 5.2 & 0.683 \\
\hline Speaks Tetun & $0>1$ & -0.001 & -0.002 & -0.001 & 0.002 & -0.013 & -0.2 & 0.005 & 0.007 & 0.018 & 0.027 & -0.261 & -2.9 & 0.498 \\
\hline Speaks Portuguese & $0->1$ & 0.002 & 0.005 & 0.003 & -0.007 & -0.036 & -0.6 & -0.002 & -0.002 & -0.006 & -0.008 & 0.090 & 1.0 & 0.288 \\
\hline Mother Bunak & $0>1$ & -0.009 & -0.020 & -0.014 & 0.027 & 0.110 & 1.9 & -0.002 & -0.002 & -0.005 & -0.007 & 0.065 & 0.7 & 0.000 \\
\hline Mother Macasae & $0 \rightarrow 1$ & -0.013 & -0.030 & -0.021 & 0.039 & 0.191 & 3.3 & -0.005 & -0.007 & -0.019 & -0.028 & 0.265 & 2.9 & 0.022 \\
\hline \multicolumn{15}{|l|}{ Community } \\
\hline Sub-district capital & $0>1$ & 0.006 & 0.012 & 0.006 & -0.016 & -0.068 & -1.4 & 0.007 & 0.009 & 0.020 & 0.026 & -0.275 & -3.7 & 0.019 \\
\hline District capital & $0>1$ & 0.040 & 0.069 & 0.006 & -0.092 & -0.448 & -4.0 & 0.006 & 0.008 & 0.018 & 0.023 & -0.213 & -1.2 & 0.257 \\
\hline Other Urban & $0>1$ & 0.008 & 0.017 & 0.008 & -0.023 & -0.119 & -1.6 & 0.003 & 0.005 & 0.011 & 0.014 & -0.196 & -1.7 & 0.572 \\
\hline Rural West & $0 \rightarrow 1$ & 0.005 & 0.010 & 0.005 & -0.013 & -0.094 & -1.3 & 0.014 & 0.017 & 0.037 & 0.044 & -0.526 & -4.6 & 0.002 \\
\hline Rural Center & $0->1$ & 0.023 & 0.046 & 0.017 & -0.061 & -0.297 & -4.8 & 0.010 & 0.013 & 0.031 & 0.039 & -0.441 & -4.6 & 0.210 \\
\hline Rural East & $0>1$ & 0.021 & 0.041 & 0.014 & -0.055 & -0.252 & -3.7 & 0.002 & 0.003 & 0.007 & 0.009 & -0.114 & -1.1 & 0.269 \\
\hline Constant & & & & & & -0.865 & -1.2 & & & & & 1.822 & 1.6 & \\
\hline
\end{tabular}

